\title{
Temporal and vertical distributions of the occurrence of the cirrus clouds over the coastal station in the Indian monsoon region
}

Saleem Ali, Sanjay Kumar Mehta* Aravindhavel Ananthavel, and Tondapu Venkata Ramesh Reddy

Atmospheric Observations and Modelling Laboratory, Research Institute, SRM Institute of Science and Technology,

5 Kattankulathur, 603203, Tamil Nadu, India

*Correspondence to: Sanjay Kumar Mehta (ksanjaym@gmail.com)

\begin{abstract}
Knowledge of the spatiotemporal coverage of the cirrus clouds is vital in quantifying the radiation budget of the earth-atmosphere system. In this paper, we present the diurnal and vertical distributions of the occurrence of the cirrus clouds during different seasons as well as its interannual variation over Kattankulathur $\left(12.82^{\circ} \mathrm{N}, 80.04^{\circ} \mathrm{E}\right)$, east coast of the Bay of

10 Bengal. The long-term (2016-2018) continuous observations of micropulse lidar (MPL) demonstrate the laminar and descending cirrus clouds that occur either as single or multiple layers. The single-layer cirrus occurrence shows a diurnal pattern with frequent occurrence in the late evening $(\sim 30-40 \%)$ while multiple-layer cirrus clouds occurrence in the early morning ( $\sim 10-20 \%)$. For the diurnal pattern in single layer cirrus cloud occurrences, convective processes dominate during the pre-monsoon, southwest (SW), and northeast (NE) monsoon seasons, while the freeze-drying process is favourable during the

15 winter season. However, both convective and freeze-drying processes are dominant in the diurnal pattern of the multiple-layer cirrus occurrences. The occurrence is maximum $(\sim 40 \%)$ during the SW and NE monsoon seasons and minimum $(\sim 25 \%)$ during the winter season. The vertical distributions indicate that the maximum occurrence is confined within the tropical tropopause layer (TTL) during all the seasons. The cirrus cloud rarely occurs above the tropopause; however, it frequently occurs below the TTL during all the seasons. The vertical extent of the occurrence has broader altitude coverage $(\sim 8-17 \mathrm{~km})$ 20 during December- March, and June-September while narrower during April-May ( $\sim 10-17 \mathrm{~km})$ and October-November ( $\sim 9$ $15 \mathrm{~km})$. The cirrus clouds occurrence also exhibits interannual variations with higher occurrence during 2016 compared to 2017 and 2018 in association with El Nino Southern Oscillation (ENSO).
\end{abstract}

\section{Introduction}

Cirrus clouds are the first clouds to interact with solar radiation. It modifies the earth's radiation budget by reflecting the incoming solar radiation (albedo effect) and trapping the outgoing longwave radiation (greenhouse effect). Therefore, the net radiative effects depend on the macrophysical, microphysical, and optical properties of the cirrus cloud (Lynch, 2002). Tropical deep convective areas are generally capped by cirrus clouds (Sassen et al., 2009) with the highest faction of optically thin ( 0.03 $<\tau \leq 0.3)$ cirrus clouds followed by optically thick $(\tau>0.3)$ and subvisible $(\tau<0.3)$ cirrus clouds. Optically thin cirrus clouds cause a net positive radiative forcing in the upper troposphere, however, thick clouds may produce cooling (Stephens and

30 Webster, 1981; Fu and Liou, 1993). Overall, cirrus clouds have net warming to the tropical atmosphere. Thus, net heating due to cirrus clouds can strengthen the upwelling and provide an alternative mechanism for the troposphere-stratosphere 
exchange process (Corti et al., 2006). Randel and Jensen (2013) reported that the occurrence of tropical tropopause layer (TTL) cirrus clouds leads to a significant increase in stratospheric water vapor. Recent studies suggest that the changes in stratospheric humidity due to cirrus clouds will substantially impact the climate variability over those associated with decadal 35 increases in greenhouse gases (Riese et al., 2012). A warming anomaly in the vertical temperature gradient can significantly decrease the cirrus fraction in the TTL, while a cooling anomaly increases it (Tseng and Fu, 2017a).

Cirrus clouds over tropical latitudes exhibit a variety of nature. Broadly, cirrus clouds are observed laminar or horizontally standing (Jensen et al., 1996), descending, and ascending nature (Nair et al., 2012). These cirrus clouds can appear either as a single-layer cloud or multi-layer clouds ( $\mathrm{Li}$ et al., 2011). The laminar cirrus clouds very close to the cold point 40 tropopause (CPT) are generally referred to as "tropopause or cold trap" cirrus (Winker and Trepte, 1998). They occur as thinto-subvisual forms under conditions of cold $\left(-70^{\circ}\right.$ to $\left.-90^{\circ} \mathrm{C}\right)$ and high $(15-20 \mathrm{~km})$ tropopause, which are rarely encountered outside the tropics. Tropopause cirrus is composed of relatively small ice crystals (Heymsfield 1986) due to the abundant moisture deposited by deep convection near the tropopause. Various dynamical process controls the generation, growth, maintenance, and decay of tropopause cirrus clouds (Liou 1986; Fujiwara et al., 2009). The descending cirrus clouds layer

45 result due to the transport of condensate from upper to middle tropospheric levels either due to gravitational settlement or atmospheric waves propagation (Heymsfield and Iaquinta, 2000; Mitchell et al., 2008). Over the tropics, the occurrence of multi-layered cirrus clouds is the highest (Nazaryan et al., 2008). These multi-layered cirrus clouds represent breaks in a vertically continuous cirrus layer due to wind shear (Jakob, 2002).

Globally, cirrus clouds cover about 50\% area with a maximum fraction of coverage over the tropics (Liou, 1986), mainly

50 within the TTL. The TTL is a region between convective outflow $(\sim 12 \mathrm{~km})$ and CPT $(\sim 17 \mathrm{~km})$. Studies indicate that cirrus clouds occur more than $\sim 80 \%$ of the time over the tropics (e.g., Nazaryan et al., 2008). A few times, cirrus clouds are also found to occur above the CPT in the lower stratosphere (Winker and Trepte, 1998; Pan and Munchak, 2011; Sandhya et al., 2015) as well as below the TTL (Dowling and Radke, 1990; Nazaryan et al., 2008). Major processes responsible for the formation of cirrus clouds are due to convectively generated remnants of the cumulonimbus outflow anvils and in-situ 55 generated by condensation and nucleation of aerosols and water vapors (Jensen et al., 1996; Lynch, 2002). In-situ generated cirrus clouds form due to homogeneous nucleation of water vapor and aerosols as ice crystals nuclei at an extremely cold temperature of $-70^{\circ} \mathrm{C}$ to $-90^{\circ} \mathrm{C}$ near the CPT (Cziczo and Froyd, 2014). Recent studies suggest that increasing aerosols concentrations in the tropopause region may significantly affect the cirrus clouds distribution (Massie et al., 2013; Vernier et al., 2015).

The occurrences of cirrus clouds maximize around the regions of intense convective activities (Spinhirne et al., 2005). The cirrus clouds frequently occur over the convectively active areas primarily associated with oceanic convection, such as equatorial Africa, South America, and southern Asia (Dessler et al., 2006). The cirrus clouds occurrence over these convective regions show a large seasonal variation which are found to be associated with the seasonal shift in the inter-tropical convergent zone (ITCZ) and midlatitude storm belts (Wylie et al., 2005; Nazaryan et al., 2008). Large-scale circulation patterns like El

65 Nino Southern Oscillation (ENSO), Quasi-Biennial Oscillation (QBO), Brewer-Dobson Circulations (BDC) also significantly 
affect the temporal variability in the occurrence of cirrus clouds (Davis et al., 2013; Tseng and Fu, 2017). For example, the occurrence of cirrus clouds over a tropical station Gadanki is found to be $\sim 44 \%$ (Pandit et al., 2014) and $~ 51 \%$ (Sunil Kumar et al., 2003) using 16 years (1998-2013) and three years (1998-2001) of ground-based lidar observations, respectively while $30-40 \%$ using the analysis of 2 years of spaceborne lidar data (Sassen et al., 2008). Such a difference in the occurrence percentage could be due to interannual variation.

The tropical convection or cloudiness shows a diurnal pattern with a peak in the afternoon to early evening over the continents and mid-night to early morning over the oceanic regions (Chen and Houze, 1997; Liu et al., 2008). Recently, Kottiyal et al. (2021) also found deep convection peaks in the late evening hours over the land. In contrast, it peaks in the afternoon hours over the majority of the oceanic regions. Such a diurnal cycle is attributed to the diurnal cycle of the net radiative forcing due to radiative heating and infrared cooling. In addition, the thermal properties of the land and ocean surfaces also play a significant role in the diurnal cycle in convective activities. Eriksson et al. (2010) observed substantial diurnal variation of the upper tropospheric humidity and ice water content over tropical land regions. Gupta et al. (2017) investigated the day-night changes in the vertical distribution of tropical clouds. They reported an enhancement in the cloud occurrence during night-time throughout the middle and upper troposphere.

The diurnal pattern in the tropical convection, upper tropospheric humidity, and ice water indicates the diurnal variation in the cirrus clouds exist. However, the complete diurnal variation of the cirrus clouds is not known yet. Thus, in the present study, we aim to make use of the continuous observations of MPL over the period 2016-2018 to disentangle the vertical distribution and diurnal variation of the cirrus clouds occurrence during different seasons as well as its interannual variations over a tropical coastal region, Kattankulathur $\left(12.82^{\circ} \mathrm{N}, 80.04^{\circ} \mathrm{E}\right)$. MPL observations indicate that laminar and descending

85 types of cirrus clouds, either in the form of a single layer or multiple-layer occur throughout the year over Kattankulathur. We focus here to examine the occurrence of the single layer and multiple layer cirrus clouds over different time scales. Our analysis also reveals that the seasonal patterns of the percentage occurrence of the cirrus clouds over the NE monsoon region are different from the SW monsoon region. The main objectives of the present study are to (i) identify cirrus clouds occurrence and study the diurnal pattern in the occurrence of the single-layer and multi-layer cirrus clouds, (ii) understand the role of convection and TTL temperature on diurnal variations of the cirrus clouds occurrence, and (iii) examine the vertical distributions of the cirrus clouds during different seasons and different years. Details about the MPL data and cirrus clouds identifications are described in Section 2. The results are discussions are illustrated in Section 3 followed by a list of conclusions summarized in Section 4.

\section{Dataset and Method of Analysis}

95 2.1 Micro Pulse Lidar (MPL)

MPL is an elastic backscatter, dual-polarization compact lidar system (model: miniMPL5231 of Sigma Space Corporation, USA) installed in the premises of SRM Institute of Science and Technology (SRMIST), Kattankulathur (12.82 $\mathrm{N}$, $80.04^{\circ} \mathrm{E}, 45 \mathrm{~m}$ above mean sea level (amsl)), on January 2016. MPL is set up at the roof of the university building $60 \mathrm{~m}$ above the ground level, i.e., at $105 \mathrm{~m}$ amsl. We have operated the MPL regularly from 15:00 IST on day one to 11:00 IST on day 
100 two. The operation was stopped during 11:00-15:00 IST to avoid the exposure of the direct solar radiation to the receiver. MPL is a diode-pumped frequency-doubled solid-state Nd: YAG laser transmitter at a wavelength $532 \mathrm{~nm}$ with low pulse energy $(3-4 \mu \mathrm{J})$ and high repletion rate $(2500 \mathrm{~Hz})$. The pulse width is set to $200 \mathrm{~ns}$ which corresponds to a range resolution of $30 \mathrm{~m}$. The telescope is of Galilean type, and its diameter is $80 \mathrm{~mm}$. We have collected lidar data at a 1-minute interval. MPL provides the measurements of the vertical and temporal distributions of the aerosols and clouds in the troposphere, which are helpful to study the atmospheric boundary layer, properties of aerosols, occurrences of clouds, and their radiative effects on the atmosphere (Campbell et al., 2003; Welton and Campbell, 2002). The detailed specification of MPL can be found in Aravindhavel et al. (2021a).

A lidar transmits short pulses of laser light into the atmosphere. The received signal due to scattering from air molecules and particles as well as the additional signal due to instrumental effects are expressed as:

$$
P(r)=P_{o} \frac{c \tau}{2} \mathrm{~A} \frac{\beta(r)}{r^{2}} \exp \left(-2 \int_{0}^{r} \alpha(r) d r\right)
$$

where $P(r)$ is the instantaneously received power (raw signal) at time $t, P_{o}$ is the transmitted power at the time $t_{o}$, c is the velocity of light, $\tau$ is the pulse duration, and $A$ is the area of the receiver. $\beta(r)$ and $\alpha(r)$ are the volume backscatter and attenuation coefficients, respectively. The received signal is corrected from system-dependent parameters such as deadtime, after pulse, the overlap corrections, as well as background noise correction are performed, and the normalized relative

115 backscatter (NRB) signal is obtained as follows:

$$
N R B=\frac{[(\text { Raw } \times \text { Deadtime })-\text { Afterpulse }- \text { Background }] \times \text { Range }^{2}}{(\text { overlap } \times \text { Laser Energy })} .
$$

Deadtime correction is done to remove the saturation effect due to the high-count rate. After-pulse correction is required to eliminate signal due to internally scattered light which saturates the detector at the beginning of each sampling, creating a blind zone in the near-field. The overlap correction occurs when the receiver field of view is inside the transmitter, causing an over-attenuated near-field signal. For our MPL system, the average overlap range is found to be $\sim 1.1 \mathrm{~km}$. More details about the calculation of the overlap factor can be found in Aravindhavel et al. (2021b). In the present study, we have used the NRB coefficients, signal-to-noise ratio (SNR), and linear depolarization ratio (LDR) during 2016-2018. The LDR is calculated as follows (Flynn et al., 2007):

$$
L D R=\left(\frac{N R B_{\text {cross }}}{N R B_{\text {co }}}\right) /\left(\frac{N R B_{\text {cross }}}{N R B_{\text {co }}}+1\right)
$$

125 Where $N R B_{c o}$ and $N R B_{\text {cross }}$ are the parallel and perpendicular components measured with linearly polarized and circularly polarized beams, respectively. The linearly (parallel) and circularly (perpendicular) polarized components of the backscattered signals are achieved by means of an actively controlled liquid crystal retarder. The polarizing beam splitter finally directs the co-polarized and depolarized signals to the detector. More details about the estimation of the LDR can be found in Flynn et al. (2007). 
In this study, upper air data was observed using radiosonde from Indian Meteorological Department (IMD) Chennai located at Meenambakkam $\left(13.0^{\circ} \mathrm{N}, 80.18^{\circ} \mathrm{E}, 16 \mathrm{~m} \mathrm{amsl}\right)$ are utilized over the period $2016-2018$. IMD Chennai is located approximately $20.13 \mathrm{~km}$ northeast of SRM IST, Kattankulathur. The daily average data from radiosonde observations at 05:30 IST and 17:30 IST is used for the background meteorological information and to obtain the TTL. Knowledge of the TTL width is important to understand the occurrence of cirrus clouds.

\subsection{Infrared Brightness Temperature (IRBT) data}

To investigate the role of deep convection on the diurnal variations of the cirrus clouds, we have used globally merged IRBT data obtained from the national weather service Climate Prediction Centre, NOAA. IRBT data is a globally-merged, fullresolution (up to $\sim 4 \mathrm{~km}$ ) IR data formed from the $\sim 11 \mu \mathrm{m}$ IR channels aboard the GMS-5, GOES-8, Goes-10, Meteosat-7, and

140 Meteosat-5 geostationary satellites. The IRBT data is available with a time resolution of one hour and spatial resolution of $0.03^{\circ} \times 0.03^{\circ}$ latitude -longitude. In this study, we have averaged the IRBT data into $0.5^{\circ} \times 0.5^{\circ}$ (latitude-longitude) centered to Kattankulathur.

\subsection{Methodology}

\section{a. Cloud base and cloud top altitudes}

145 NRB profiles from the MPL observations are used to identify the cirrus cloud layers based on the differential zero-crossing method (Pal et al., 1992). This method is based on the fact that the NRB signal intensity generally decreases monotonically with altitude until a cloud appears. When the signal encounters a cloud, the NRB signal level begins to increase significantly due to the larger cloud droplet than the ambient air. As a result, the cloud-base height of the lowest cloud is identified using MPL observations directly as the change in the slope or gradient (the first derivative) of NRB (i.e., dNRB/dZ) referred to as the differential zero-crossing method (Dai et al., 2017; Nair et al., 2012; Platt et al., 1994; Wu et al., 2015). To identify the base of the cirrus clouds over the tropics, we limit the lowest altitude to $8 \mathrm{~km}$. Over the tropics, cirrus clouds usually occur at a temperature below $-20^{\circ} \mathrm{C}$, corresponding to an altitude above $8 \mathrm{~km}$ (Liou, 1986; Lynch, 2002; Pandit et al., 2014).

We have sampled the NRB profiles at the resolution of $30 \mathrm{~m}$ that includes several high-frequency variations and background noise. These small-scale fluctuations are smoothed by employing 10 points (width $300 \mathrm{~m}$ ) running mean filter to the first derivative of the NRB signal. The base, top, and peak of the cirrus clouds are identified by the differential zero-crossing method from the smoothed NRB signals. The NRB signal starts to increase relative to the threshold value at the cloud base, while at the apparent cloud-top, the NRB signal comes down to the threshold level. The cloud-base and cloud-top altitudes are only identified when the NRB gradient increases and decreases relative to the threshold value for at least three consecutive range bins $(90 \mathrm{~m})$, respectively. The threshold value is taken as the mean plus two standard deviations of the background NRB signal from ambient air. To avoid detecting any spurious layer, we make sure that the NRB signals possess a good SNR value. The level up to which the NRB signals are more than the one standard deviation of the column integrated signal is considered good SNR. In general, a good SNR is found up to $\sim 15-20 \mathrm{~km}$ during night-time (Aravindhavel et al., 2021a). However, for daytime, good SNR is found to be only $\sim 4-6 \mathrm{~km}$ due to the high solar irradiance except for the occasion of the occurrence of cirrus 
clouds. Whenever cirrus clouds occur during the daytime, the SNR value increases within the cloud boundaries and qualifies

165 the criteria of good SNR.

The apparent cloud-top height is detected by searching the first level where the NRB value is just less than or equal to the NRB value at the cloud base. In the cases of multiple cirrus clouds, the NRB profile may reveal several peaks. However, each of these peaks may not be really associated with separate cloud layers. The distinct multiple cirrus cloud layers are detected only when they are separated with a clear air region, i.e., NRB signal must drop to background level. Finally, LDR values were

170 checked for each cloud layer identified using the differential zero-crossing method that LDR within the cirrus layer should be at least 0.05 greater than the LDR from the ambient air outside the cloud boundaries, with a minimum absolute value of 0.08 (Sassen and Cho, 1992; Nair et al., 2012).

\section{b. Cloud optical thickness}

175 Once the cirrus cloud base and top altitudes are identified, cirrus cloud optical thickness is derived using the two-way transmittance method (Young, 1995). The optical thickness is half of the logarithm of the ratio of NRB signals just below the cloud base to that immediately above the cloud top. Note that the NRB is the range corrected signal that has passed through the system and overlap corrections. The molecular and aerosol contributions to the altitude variation of NRB are also removed before calculating the optical thickness. Using the transmittance method, optical thickness is thus obtained without inverting the lidar signals and requirement of the knowledge of the lidar ratio. We have obtained the altitude profiles of the molecular coefficient using the monthly mean temperature and pressure profiles. For aerosol contribution to NRB signal, we have used the seasonal mean altitude profiles of aerosol extinction coefficient derived from MPL observations over the site (Aarvindhavel et al., 2021a; Aarvindhavel et al., 2021b). However, it is to be noted that the molecular and aerosol contributions to the NRB signal are very small compared to cirrus clouds occurring above $8 \mathrm{~km}$ (Young, 1995; Nair et al., 2012). We have employed only nighttime profiles having very good SNR to determine the optical thickness. Whenever low SNR is observed, time averaging of the NRB signals is done to reduce the noise level and improve the SNR before the calculation of the optical thickness (Nair et al., 2012).

\section{c. Percentage of occurrence of cirrus clouds}

Once the cirrus cloud base and top altitudes are identified, the height and time functions of the monthly percentage occurrence of the cirrus clouds (POC) are calculated. For this, we have segregated the total hours of MPL and the cirrus clouds observations between 14:00 IST on day one to 11:00 IST on the second day month-wise during 2016-2018. We have obtained 665 days of MPL data that are continuously operated for one hour, i.e., in total, 11778 hours of MPL observations are collected. Out of which 496 days with cirrus clouds duration longer than half-hour is observed, i.e., in total 5002 hours of cirrus clouds

195 observations are found. The POC is the ratio of the total hours of the cirrus clouds to the total hours of the MPL operation multiplied by 100 . We have counted the total hours of the cirrus clouds in the altitude bins of $30 \mathrm{~m}$ from cloud-base to cloud- 
top occurring between $8 \mathrm{~km}$ and $20 \mathrm{~km}$ and in the time interval of 5 mins between 14:00 IST on day one to 11:00 IST on the second day.

\section{d. Tropopause Parameters}

The tropopause parameters such as the CPT, convective tropopause (COT), and the TTL are obtained using radiosonde temperature profiles at 05:30 IST and 17:30 IST over the period 2016-2018. CPT is defined as the minimum temperature level in the troposphere (Selkirk et al., 2003), and COT is defined as the minimum potential temperature gradient (Mehta et al., 2011). The region between the COT and CPT levels is called TTL.

\section{Results and discussion}

\subsection{Background meteorological information}

Figure 1 shows the monthly mean variation of the temperature, relative humidity $(\mathrm{RH})$, zonal wind, meridional wind, potential temperature gradient from surface to the altitude $25 \mathrm{~km}$ along with rainfall, outgoing longwave radiation (OLR), CPT, and COT altitudes over IMD Chennai. The monthly mean CPT and COT altitudes are obtained by averaging the daily data. Kattankulathur (Chennai) is a coastal station that experiences rainfalls both from the southwest (SW) monsoon during JuneSeptember (JJAS) and north-east (NE) monsoon during October-November-December (OND). Thus, the prevalence of both the monsoons results in an abundant supply of moisture into the upper troposphere favorable for the cirrus clouds formation. The study region is also influenced by the sea breeze that triggers the local convective rainfalls (Reddy et al., 2020; Simpson

215 1994) over Kattankulathur. The temperature shows a substantial seasonal variation at the surface, within the atmospheric boundary layer $(\mathrm{ABL} \sim 2.0 \mathrm{~km})$, and within the TTL. In the mid-troposphere, seasonal variation in the temperature is very weak (Aravindhavel et al., 2021a; Aravindhavel et al., 2021b). The surface temperature becomes minimum $\left(\sim 25.9 \pm 0.3^{\circ} \mathrm{C}\right)$ during December-January and maximum $\left(\sim 31.6 \pm 0.6^{\circ} \mathrm{C}\right)$ during April-May-June, with May is the hottest month. The frequent sea breeze during pre-monsoon seasons (March-April-May; MAM) decreases the temperature within the $0.6 \mathrm{~km}$ (average 220 height of the thermal internal boundary layer (TIBL) (Reddy et al., 2020)). The monthly mean temperature in the TTL shows the marked seasonal variation with minimum CPT temperature ( $190 \pm 2 \mathrm{~K})$ during October to May (covering NE monsoon, winter (January -February), and pre-monsoon seasons) and maximum CPT temperature ( 192 $\pm 2 \mathrm{~K})$ during June-September (SW monsoon). The monthly mean temperature shows a marked wider cold point region between $\sim 16.1$ and $18.7 \mathrm{~km}$ during October -May, which becomes a narrow region between 16.4 and $16.9 \mathrm{~km}$ during June-September. The CPT altitude is higher $225(\sim 17.5 \pm 0.5 \mathrm{~km})$ during the winter season and lower $(16.7 \pm 0.4 \mathrm{~km})$ during the $\mathrm{SW}$ monsoon season. The COT altitude also shows a strong seasonal variation with minimum altitude $(\sim 11.2 \pm 1.4 \mathrm{~km})$ from December to April and maximum altitude $(12.2 \pm 1.6 \mathrm{~km})$ from May to December. The COT altitude starts to increase in May, during which rainfall is observed due to isolated convections, mainly thunderstorms. The relative humidity is found to be greater than $70 \%$ within the TIBL throughout 
the year. Above the ABL, the mid-troposphere is almost dry, with $\mathrm{RH}<20 \%$ from December to April. The atmosphere is moist from May to mid-November with RH $>50 \%$ due to strong convection during the SW monsoon and NE monsoon seasons. Within the TTL, RH is found to be minimum. However, RH is relatively more $(\sim 60 \%)$ near the CPT, indicating the uplift of the moist air near the CPT due to convection during the SW monsoon season. The humid air can also advected to near CPT due to tropical easterly jet (TEJ) during the SW monsoon season. The TEJ core (zonal wind speed $>30 \mathrm{~m} / \mathrm{s}$ ) is located near the CPT during this season. Over Chennai, northwesterly prevails up to $10 \mathrm{~km}$ except near the surface throughout the year with maximum speed during the SW monsoon season. During the pre-monsoon season, the wind near the surface is southwesterly due to the frequent occurrence of the sea breeze (Reddy et al., 2020). The westerly/southwesterly (easterly/northeasterly) prevails during November-April (June-September) above $10 \mathrm{~km}$. During the SW monsoon season, the low-level jet (LLJ) stream in the lower troposphere and TEJ stream in the upper troposphere dominate. The monthly mean of the potential temperature gradient shows distinct minima around the connective tropopause. The temperature gradient starts to increase above the CPT. The CPT altitude marks the location where the potential temperature gradient drastically changes from low to high value.

\subsection{Detection of cirrus cloud layers from NRB signals}

The identification of the cirrus cloud layer is illustrated for different types of the cirrus clouds cases such as the laminar cirrus, descending cirrus, broad cirrus and multi-layered cirrus observed on 12 February 2018, 27 May 2016, 03 August 2017, and 26 July 2016, respectively as shown in Figure 2. It shows the time height section of the NRB signals over the altitude $0.3-22 \mathrm{~km}$ observed on 14:00 IST on the first day to 11:00 IST on the second day, vertical profiles of the NRB signal, $\frac{d N R B}{d Z}$, and SNR at 01:30 IST using MPL observation along with the daily mean temperature, potential temperature, and its gradient.

On 12 February 2018 (Fig. 2a), we have observed the laminar cirrus clouds layer between the altitudes $\sim 11.0 \mathrm{~km}$ (cloud base) and $13.5 \mathrm{~km}$ (cloud top) from 18:00 IST to 08:00 IST. During this day, a typical case of the winter season, relatively higher concentrations of the aerosols dominate within the ABL $(\sim 2.0 \mathrm{~km})$. Above it up to $\sim 3-4 \mathrm{~km}$, a diffuse regime of the more aged aerosols (Jacob et al., 2002) dominates. Above $4 \mathrm{~km}$, aerosol concentrations are extremely low, and the signal is mainly dominated due to molecular scattering and the presence of the clouds. The NRB profile observed at 01:30 IST shows the monotonic decrease of the signal above the $\mathrm{ABL} \sim 2.0 \mathrm{~km}$ to the cloud-base height $\sim 11.6 \mathrm{~km}$. The first derivative of the NRB begins to increase at the cloud base. At the cloud peak, $\frac{d N R B}{d Z}$ shows zero-crossing i.e. change in sign from positive to negative. One can notice that several zero crossings are present below the cloud base that arise from inhomogeneity in the background aerosols. However, these insignificant zero crossings are below the level of the threshold value and is rejected. The cloud peak at $\sim 12.8 \mathrm{~km}$ is identified as the level of zero crossings of $\frac{d N R B}{d Z}$ where it changes the sign from positive to negative. The apparent cloud-top height is identified at $13.6 \mathrm{~km}$. At the cloud-top height, NRB value was found to be $\sim 0.12$ counts $\mathrm{km}^{\wedge} 2 / \mu \mathrm{s} \mu \mathrm{J}$ much lesser than the NRB value $\sim 0.85 \mathrm{~km}^{\wedge} 2 / \mu \mathrm{s} \mu \mathrm{J}$ at the cloud-base. The detected cloud-base and cloud- 
top heights during 18:00 IST to 8:00 IST are superimposed in the contour plot. On this day, both subvisible $(\tau \leq 0.03)$ and optically thin $(0.03<\tau \leq 0.3)$ cirrus clouds are present with mean optical thickness $\sim 0.05 \pm 0.04$. The cirrus cloud is observed near the convective tropopause (COT altitude $\sim 11.7 \mathrm{~km}$ ). The temperature and potential temperature of the cloud layer are $\sim$ $216 \mathrm{~K}$ and $347 \mathrm{~K}$, respectively. The cold point tropopause (CPT altitude $\sim 17.3 \mathrm{~km}$ ) lies much above the cirrus cloud top.

On 27 May 2016 (Fig. 2b), we have observed the descending type cirrus clouds layer, which descended from altitude with cloud-base $\sim 13.5 \mathrm{~km}$ and cloud-top $\sim 15.0 \mathrm{~km}$ at 16:00 IST to the altitude with cloud-base $\sim 11.0 \mathrm{~km}$ and cloud-top $\sim 12.0$ $\mathrm{km}$ at 08:00 IST. The cirrus clouds, while descending, change their vertical structure and optical thickness. The NRB profile observed at 01:30 IST shows high aerosol concentrations up about $6 \mathrm{~km}$, a typical feature during monsoon seasons over Kattankulathur. During this season, strong convection and strong southwesterly wind prevail, bringing enormous amounts of moisture-laden coarse particles from the Arabian sea and the Bay of Bengal (Aravindhavel et al., 2021a, 2021b). Above it, the NRB signal decreases until it encounters the cloud. The identification of the cirrus clouds layer is similar to as mentioned in the previous case. The heights of cloud-base, cloud peak, and cloud-top are at $\sim 12.2 \mathrm{~km}, 12.9 \mathrm{~km}$, and $\sim 13.9 \mathrm{~km}$, respectively. In this case, the NRB value at the cloud-top is $\sim 0.15$ counts $\mathrm{km}^{\wedge} 2 / \mu \mathrm{s} \mu \mathrm{J}$ lesser than at cloud-base $\sim 0.21 \mathrm{~km}^{\wedge} 2 / \mu \mathrm{s} \mu \mathrm{J}$. The detected cloud-base and cloud-top altitudes from 16:00 IST to 08:00 IST are superimposed over the contour plot. We have observed mostly optically thin $(0.03<\tau \leq 0.3)$ and thick clouds $(\tau>0.3)$ with mean cloud optical thickness $\sim 0.13 \pm 0.07$. In the beginning, the cirrus clouds lie within the TTL (COT altitude $\sim 11.9 \mathrm{~km}$, CPT altitude $\sim 17.1 \mathrm{~km}$ ); however, while descending, it falls below the TTL base at 02:00 IST, and the layer reaches just below the TTL at 08:00 IST. The mean cloud temperature before the descent is $209 \mathrm{~K}$, and after the descent is $232 \mathrm{~K}$.

On 03 August 2017 (Fig. 2c), a broad layer of cirrus clouds was observed having cloud-base $\sim 10.5 \mathrm{~km}$ and cloud tops $\sim 12.5 \mathrm{~km}$ at 15:00 IST and $\sim 17.0 \mathrm{~km}$ at 01:00 IST. On this day, cirrus clouds appear to present even before the 14:00 IST; however, MPL was not operated during this time due to high solar radiation, as mentioned earlier. The subvisible cirrus clouds above $13 \mathrm{~km}$ during mid-night to early morning may have formed either due to a decrease in ambient air temperature or reappearance of the existing cirrus with a decrease in the optical thickness of the lower-level cirrus clouds. It is to be noted that the MPL signal is unable to penetrate deep enough in the presence of the optically thick cirrus clouds. This is the limitation of the up-looking lidar resulting in ambiguous detection of the cirrus-top and is generally referred to as apparent cirrus top (Pal et al., 1992). However, in the cases of the subvisible cirrus clouds and thin cirrus clouds, actual cloud-top can be detected as observed on 12 February 2018 (Fig. 2a). From surface to $\sim 3$ km, high aerosol concentrations are observed. As this typical case is observed in the SW monsoon season, increased water vapor and aerosols are transported to this region due to prevailing strong southwesterly wind and strong convection, as mentioned in the previous case. The presence of mid-tropospheric thick clouds and boundary layer clouds substantially attenuates the lidar signal. The NRB profile observed at 01:30 IST monotonically decreases above the boundary layer until it encounters the cirrus cloud with the base at $\sim 10.5 \mathrm{~km}$. Unlike previous cases, in this case, two peaks at $\sim 12.0 \mathrm{~km}$ and $\sim 16.0 \mathrm{~km}$ are discernible; however, they do not represent the multiple cirrus layer. Because there is no clear sky region between these peaks, the signal never reaches the background value. The NRB value between these peaks never became less than the NRB value at the cloud base. Hence, the cloud-top height is 
295 identified at $16.95 \mathrm{~km}$. The value of the NRB at the cloud-top is 0.05 counts $\mathrm{km}^{\wedge} 2 / \mu \mathrm{s} \mu \mathrm{J}$, much lesser than the value $(0.15$ counts $\left.\mathrm{km}^{\wedge} 2 / \mu \mathrm{s} \mu \mathrm{J}\right)$ at cloud-base. The detected cloud layers are shown in the contour plot. Mostly optically thin and thick clouds with mean cloud optical thickness $\sim 0.12 \pm 0.07$, similar to the previous case is also observed in this case. Similar to the previous case, the cirrus cloud layer was found within the TTL (COT altitude $\sim 10.8 \mathrm{~km}$, CPT altitude $\sim 16.8 \mathrm{~km}$ ) with cirrus top during midnight to early morning nearly coincides with CPT. In this case, CPT is found to be shaper and colder than the previous cases, with cirrus clouds occurring below the CPT. The mean temperature of the cloud layer is found to be $\sim 213 \mathrm{~K}$.

On 26 July 2016 (Fig. 2d), the multiple cirrus layers were observed from 22:00 IST to 06:00 IST. In this case, the cirrus layer appears to present before 15:00 IST on the first day and after 11:00 IST on the second day; however, lidar was switched off due to high solar radiation, missing the complete diurnal feature. The cirrus cloud base and top heights are at $~$ $10 \mathrm{~km}$ and $\sim 12 \mathrm{~km}$, respectively, at 15:00 IST, which increases to $\sim 14 \mathrm{~km}$ (cloud-base) and $\sim 16 \mathrm{~km}$ (cloud-top) at 20:00 IST and remain as laminar till morning 8:00 IST. During 22:00 - 06:00 IST, another cirrus layer with cloud-base $\sim 10.0 \mathrm{~km}$ and cloud-top 13.5 km appeared. About 06:00-08:00 IST, a convective cloud is observed at an altitude of about 4-6 km. From 08:00-11:00 IST, a cirrus layer appears whose cloud-base increases from $8.0 \mathrm{~km}$ to $11.0 \mathrm{~km}$ and the cloud-top increases from $10.0 \mathrm{~km}$ to $14.0 \mathrm{~km}$. The cirrus clouds observed show a significant variation in the optical and geometrical thickness related to temperature, moisture, and convective strength. In this case, we observed a disturbed boundary layer feature with highly

310 variable aerosol concentrations. The NRB profile observed at 01:30 IST shows high aerosol concentrations up to $\sim 3.0 \mathrm{~km}$, which decreases monotonically above it until encountering the cirrus cloud-base at $\sim 11.0 \mathrm{~km}$. We observed the two peaks at $\sim 11.6 \mathrm{~km}$ and $\sim 12.8 \mathrm{~km}$ for the lower cirrus layer, similar to the previous case. However, as mentioned previously, it represents a single cirrus layer. Similarly, the upper cirrus layer also contains two peaks at $\sim 16.0 \mathrm{~km}$ and $16.8 \mathrm{~km}$; however, it also represents a single cloud layer. Between cloud top of the lower cirrus layer and cloud-base of upper cirrus layer, clear sky air

315 observed with signal return from clear sky ambient air present. Thus, these two layers are multiple cirrus layers, and the detected cloud-base and top heights are shown in contour plots. In this case also optically thin and thick clouds with mean cloud optical thickness $\sim 0.17 \pm 0.31$ are observed. Interestingly, both cirrus layers occur mainly within the TTL (COT altitude $\sim 12.0 \mathrm{~km}$, CPT altitude $\sim 17.1 \mathrm{~km}$ ). However, part of the cirrus top of the upper layer appears just above the CPT, and part of the lower cirrus layer appears just below the COT. In this case, the temperature profile shows relatively broader tropopause. Within the TTL, the potential temperature gradient shows significant enhancement. The average temperature of the lower and upper cirrus layers is $\sim 226 \mathrm{~K}$ and $197 \mathrm{~K}$, respectively. The upper layer occurs near the tropopause and is generally referred to as the tropopause cirrus.

\subsection{Diurnal and Day-to-Day patterns of the cirrus clouds occurrence}

325 We applied the above-mentioned zero-crossing method to detect the cirrus clouds layers for all the observations over the period 2016-2018. Figure 3 shows the day-to-day variation of the total duration of the first layer or single layer cirrus clouds observations and the total duration of the MPL observations during 2016-2018. MPL is operated between 14:00 IST on day 
one to 11:00 IST on day two on clear sky conditions. The maximum duration of MPL is 20 hours. However, on several occasions, MPL operation is stopped either due to technical issues or bad weather. The major data gaps are during February, June, December 2016, July, October, November 2017, and April and September 2018. Note that we have plotted only those days having lidar operation more than 1 hour and cirrus clouds observations more than half hour. Some noticeable differences can be seen on cirrus clouds occurrence among 2016, 2017, and 2018, indicating a robust interannual variation. During January-February, cirrus clouds frequently occurred during 2016 and 2018 when compared to 2017. While during MarchApril, cirrus clouds duration and occurrence are more during 2016 and 2017 compared to 2018. During May-June, all the years

335 show the relatively longer duration of the cirrus clouds occurrence.

Figure 4 shows the timings of the single and multiple layers of the cirrus clouds occurrence and its day-to-day variations during 2016-2018. We referred to 'single' for the one-layer clouds and the first layer in the case of the multiple cirrus clouds. At the same time, 'multi' is referred for the second layer of cirrus clouds in the cases of multiple cirrus layers. The occurrence of the third layer was rare and is not considered in this study. The purpose of showing different colors in the left column panels is only to distinguish the day-to-day occurrence of the cirrus clouds. The single-layer cirrus clouds appear to occur throughout the year. However, multiple layer cirrus clouds occur mainly during May to August, followed by occurrence in OctoberNovember. It can be seen that cirrus clouds sometimes occur throughout the night and sometimes during early evening, and sometimes during the early morning. To understand the overall occurrence frequency, we have calculated the percentage of the occurrence between 14:00 IST on day one to 12:00 IST on day two at an interval of every 2 hours. The occurrence frequency is displayed at 15:00, 17:00, 19:00 IST, and so on in the right column panels of Figure 4. It is to be noted that the occurrence of the cirrus clouds during daytime is affected by the high solar noise which has significantly reduced the MPL detection capability of the cirrus clouds especially thin and subvisible cirrus clouds. Thus, the occurrence of the cirrus clouds after the sunrise and before the sunset is presented here just for completeness and may not represent accurate statistics. The overall occurrence of the single-layer cirrus clouds reveals that it occurs more frequently during the evening hours (18:00-20:00 IST).

350 At the same time, multi-cirrus clouds layer occurs more frequently during early morning hours (04:00-06:00 IST). The diurnal occurrence of the cirrus clouds shows variation in terms of amount and pattern among the years 2016-2018. The occurrence of both single and multi-layer cirrus clouds was more during 2016 when compared to the occurrence during 2017 and 2018 . It is to be noted that the diurnal structure of the cirrus occurrence is of its first in kind, and we have not come across any such study before in our knowledge.

355 As mentioned earlier in the introduction that the cirrus clouds are either convectively generated or in-situ formed. The convectively generated cirrus develops mainly due to the remnant of the anvil clouds following the deep convections, while in-situ formed cirrus forms due to extremely cold TTL temperature. In this section, we have examined the possible roles of the convection and TTL temperatures on the diurnal variation of the cirrus clouds occurrence during different seasons. The diurnal variation of the occurrence of the single and multi-layer cirrus clouds, occurrence of the IRBT less than $240 \mathrm{~K}$ and 220

$360 \mathrm{~K}$ during different seasons and month-wise occurrence of the CPT temperature less than 191 $\mathrm{K}$ at 05:30 IST and 17:30 IST (evening) are calculated as shown in Figure 5. During the winter and SW monsoon seasons, the cirrus clouds occur more 
frequently in the late evening $\sim$ 18:00-20:00 IST. While during the pre-monsoon season, cirrus clouds uniformly occur throughout the night. For the NE monsoon season, cirrus clouds occur more frequently during the late evening and early morning (04:00-06:00 IST). The SW monsoon season also shows relatively enhanced occurrence during the early morning hours, similar to the NE. The multi-cirrus clouds occur more frequently during the SW monsoon than all other seasons with a similar frequency. The diurnal variation of the occurrence of the multi-cirrus shows pronounced maxima in the early morning hours.

To understand the role of the convection on the occurrence of the cirrus clouds, we have obtained the occurrence of the IRBT less than $240 \mathrm{~K}$ representing the convective clouds with cloud top above $8 \mathrm{~km}$ and IRBT less than $220 \mathrm{~K}$ representing the deep convection with cloud top above $12 \mathrm{~km}$ (Ali et al., 2020). The convective clouds and deep convections frequently occur during the SW monsoon season, followed by the NE monsoon and pre-monsoon seasons. During winter seasons, convections are rare. During the SW and NE monsoon seasons, the diurnal pattern of the convection is similar. In these seasons, convection frequently starts late morning and remains prevailing until midnight, with maximum occurrence from late evening to midnight. The daytime convection during the SW and NE monsoons can be related to the higher occurrence of cirrus clouds in the late evening hours. At the same time, the maximum occurrence of the deep convection during midnight may be related to the cirrus occurrence during the early morning hours. During the pre-monsoon season, convection mainly occurs in the daytime resulting in uniform cirrus occurrence throughout the night. However, though there is no convection during the winter season, cirrus clouds frequently occur during the late evening, similar to the SW and NE monsoon seasons. To understand it, we examined the role of the freeze-drying processes on the formation of the in-situ formed cirrus clouds by calculating the occurrence frequency of the cold point tropopause (CPT) temperature less than $191 \mathrm{~K}$ during morning and evening hours. This CPT temperature $<191 \mathrm{~K}$ believes to be the threshold value of the freeze-drying of the water vapor that can lead to the formation of the cirrus clouds. We observed that the CPT temperature frequently becomes colder than $191 \mathrm{~K}$ from November to May than during June to October. Such cold temperature in the TTL region may be conducive for the in-situ formed cirrus clouds during winter and pre-monsoon season. The CPT temperature $<191 \mathrm{~K}$ frequently occurs in the morning than in the evening hours during all the seasons. The frequent occurrence of multiple layer cirrus clouds during morning hours can also be partly related to the CPT temperature $<191 \mathrm{~K}$. As multiple-layer cirrus always occurs at a higher altitude. Thus, the in-situ formed clouds (due to CPT temperature $<191 \mathrm{~K}$ ) may result in multiple layer cirrus at a higher altitude during the SW monsoon season, similar to the single-layer cirrus that occurs during the winter season. Additionally, the higher occurrence during early morning hours appears related to the strong turbulence responsible for transporting the aerosol and water vapor near the CPT (Parameswaran et al., 2004). Such cirrus clouds are known to persist for a longer duration.

To understand the altitude distribution of the diurnal variation of the cirrus clouds occurrence during different seasons, we have calculated its percentage occurrence for each month from January to December over the period 2016 to 2018, as shown in Figure 6. We have calculated the monthly POC from 14:00 IST on day one to 11:00 IST on day two, covering the entire night above $8 \mathrm{~km}$. Note that we have shown the plot from the altitude of $5 \mathrm{~km}$ to $20 \mathrm{~km}$. The monthly mean CPT and 
395 COT heights and standard deviations obtained using daily average IMD radiosonde data are also embedded in Fig.6. As mentioned earlier, the vertical and diurnal structure of the occurrence is calculated by taking the ratio of the total number of cirrus clouds observed to the total number of observations for every $5 \mathrm{~min}$ and $30 \mathrm{~m}$ altitude intervals in a given month for the period 2016-2018. Note that the occurrence is only calculated for MPL operation longer than 1 hour and the cirrus presence longer than half-hour. The POC show high temporal and vertical structures during each month. In general, it is found to be

400 between $\sim 10-30 \%$, with the highest occurrence during May-June and the lowest occurrence during February-March.

During the winter season (December to February), POC is observed from the first day evening ( 17:00 IST) to the next day morning ( $\sim 08: 00$ IST) over the altitude $\sim 8-17 \mathrm{~km}$. It is found to be $\sim 10-25 \%$, with the highest POC over the altitude $\sim 14-16$ $\mathrm{km}$ just below the mean CPT altitude $(17.2 \mathrm{~km})$ throughout the night (18:00-06:00 IST). The highest POC over such a narrow region indicates the frequent occurrence of the optically thin laminar cirrus (Sivakumar et al., 2003) due to an increase in sedimentation with a decrease in CPT temperature. It can be seen that the POC very close to the CPT doesn't occur before the evening hours and after the morning hours. It could be either due to dissipation of the very thin optically cirrus clouds with sunrise or due to limited detection capability of MPL under the solar noise. The decrease in POC just below the CPT during early morning hours supports the contention. It also indicates that the cirrus clouds closer to CPT are generally optically thin, which does not descend but lasts longer. Besides it, the higher POC is also noticed at $\sim 8$-12 km 16:00-19:00 IST and $\sim 02: 00$ -

410 07:00 IST. Though cirrus clouds are mainly optically thin during the winter season, a few times, cirrus appears descending due to an increase in the load of sedimentation that gets deposited at the COT altitude and dissipated at lower altitude due to an increase in temperature (Nair et al., 2012). The occurrence of the different types of the cirrus clouds, such as descending and laminar cirrus clouds, we are planning to report in a separate study. At the same time, the higher POC near the COT during the evening and early night hours that last for a shorter duration appear to be locally generated due to turbulence (Satheesan

415 and Krishna Murthy, 2002).

The POC during March is found to be minimum (10-15\%); however, it extends from 8-16 km, similar to all the other months. POC during March shows two distinct layers; the first one within the TTL and the second one just below the TTL base. Compared to previous months, the POC significantly improved from April to May, with the maximum occurrence confined within TTL.

During June-September, the cirrus clouds frequently occur between 14:00 IST on day one to 11:00 IST on day two compared to the rest of the months. The POC varies between 10-30\% during June, with the highest occurrence observed at night. The POC is limited to height $8-14 \mathrm{~km}$ during the daytime; however, it is in the altitude range of $8-17 \mathrm{~km}$ during nighttime. The diurnal variation of the temperature in the upper troposphere (Mushin et al., 2017) seems to be the controlling factor of the higher occurrence and greater extent of the cirrus clouds during nighttime compared to daytime. The limited vertical extent of the daytime POC could be due to the limitation of the lidar to detect the cirrus due to high solar noise. Note that during the SW monsoon season, deep convective clouds such as cumulonimbus clouds frequently occur at the same height $(\sim 8-10 \mathrm{~km})$ (Subrahmanyam and Kumar, 2013) at which cirrus clouds also occur. To avoid including such clouds, we have carefully 
examined the LDR to distinguish the cirrus clouds from the cumulonimbus clouds having high optical thickness. Cirrus clouds occur (i) sometimes above the CPT, (ii) several times below the mean TTL, and (iii) frequently as multi-layered cirrus clouds during the SW monsoon season. Multi-layered cirrus clouds occur with the upper layer close to CPT and the lower layer close to COT. During June-August, the upper layer of the POC mainly persists after the sunset and before the sunrise ( 17:00-05:00 IST).

In contrast, the lower layer of the POC occurs even before sunset and after sunrise. It indicates that the upper layer

435 POC or the multiple cirrus clouds disappear after sunrise due to its dissipation by solar heating. However, the lower POC layer persists throughout the day and night, indicating the role of the high moisture available during the SW monsoon season. The higher POC during the SW monsoon season, when compared to the rest of the seasons, mainly appears due to the largescale convection and the upper tropospheric anti-cyclonic circulation (Parameswaran et al., 2003; Satheesan and Murthy, 2002).

The POC has a limited vertical extent during the transition (October) from the SW monsoon season to the NE monsoon season. It is generally confined within the TTL with fewer or no occurrence of the cirrus clouds above the CPT. During October, zonal wind in the upper troposphere changes to weak easterlies (Sunilkumar et al., 2010), decreasing the moisture due to horizontal transport from the Bay of Bengal significantly reduces the POC. The inadequate supply of moisture due to the weakening of the local convection reduces the sustenance of cirrus clouds. However, relatively higher POC during

445 November appears due to the prevalence of the NE monsoon over Kattankulathur. The convection during the NE monsoon is not as strong as the SW monsoon leading to the formation of the cirrus clouds at relatively lower heights during November.

Overall, the POC varies from $20 \%$ to $40 \%$, except during March and October months with low occurrence. It is worth mentioning here that the less value of the POC is found to be during the months when the zonal wind pattern transits from westerly to easterly (easterly to westerly) in the upper troposphere during March (October) over the Indian monsoon region

450 (Goswami, 2005). It is well known that the zonal wind shear significantly changes the TTL temperature and hence the cirrus clouds occurrence (Randel et al., 2002) by uplifting the humidity to the upper troposphere, which provides a favorable condition for the formation of in-situ cirrus clouds (Das et al., 2011). We have also examined the zonal wind shear using radiosonde observations at IMD Chennai $\left(13.0^{\circ} \mathrm{N}, 80.18^{\circ} \mathrm{E}\right)$. Supplementary Figure S1 indicates maximum shear within 8-16 $\mathrm{km}$ from May to September, consistent with POC. However, note that large-scale circulations and wave activities can also

455 modulate TTL clouds (Held and Hoskins, 1985; Kim et al., 2013). Podglajen et al. (2018) observed that the gravity waves affect the distribution of ice particles and found that the cirrus clouds are primarily confined in the altitude region where water vapor is saturated in association with positive zonal wind anomalies.

\subsection{Vertical structure of the POC during different seasons}

460 Figure 7 shows the vertical extent of the cirrus occurrence, monthly mean and standard deviations of the altitudes of cloud base and top, CPT and COT, and monthwise total observations of MPL and cirrus the occurrence of the single and multi- 
layered clouds. It can be seen that POC has a greater vertical extent during January, February, March, June-September, and December while relatively lesser vertical extent during April-May and October- November. The POC is found to be lower from December to March and higher during April- November. The peak of the POC varies during different months. The monthly variation of the altitude of the peak of the POC shows a strong seasonal variation with higher altitude during the winter season and lower altitude during the SW monsoon season.

The cirrus clouds occur at higher altitudes from January to April, during which the dry season prevails over Kattankulathur. During this time, the cloud base and cloud top altitudes (referred as CBH and CTH in Figure 7b) show nearly in phase variation with COT altitude. It indicates the main convective outflow provides a conducive mechanism for the formation of the cirrus clouds. However, from May to November, Kattankulathur remains wet due to the frequent rainfalls from SW and NE monsoons. The strong convection during SW and NE monsoons pushes the COT altitude relatively at a higher altitude (Mehta et al., 2011). During this time, mean cloud base altitude occurs at an altitude $\sim 1-2 \mathrm{~km}$ lower than the COT. During the SW and NE monsoon seasons, the large moisture availability in the mid-troposphere results in the formation of the cirrus clouds at lower levels. However, during these seasons, multiple cirrus clouds frequently occur. It can be seen that though multiple cirrus clouds occur throughout the year, their frequencies are less than $10 \%$ except for May-August. The POC for the multiple cirrus clouds are found to be 19\%,17\%,15\%, and 14\% during May, June, July, and August, respectively (Fig 7d). In the monthly mean occurrence profiles, the double peak is only discernible during July-August. It is because both single and multi cirrus clouds have the same frequency during July-August. While for other months, POC for multi-cirrus is much lower than single-layer cirrus clouds. Both single and multi-cirrus clouds layer vary in phase with CPT height and roughly out of phase with COT altitude during May-December. Note that in total, every month, MPL is operated more than $746 \mathrm{~h}$ with a maximum duration of $\sim 1393 \mathrm{~h}$ during March over the period 2016-2018 (Fig. 7c).

Figure 8 shows the altitude distribution of the POC during different seasons such as DJF, MAM, JJA, and SON. It can be seen that the detailed vertical extent of the POC observed during different months, as shown in Figure 7, is absent when the POC is calculated season-wise. The overall POC profile shows that the cirrus clouds occur mostly within 8-17 km, with a maximum POC of about $25 \%$ in the altitude range $13-15 \mathrm{~km}$ (a broad peak). It is observed that the POC gradually increases from $8.0 \mathrm{~km}$ to about $\sim 13-15 \mathrm{~km}$ and drastically decreases above it to about $17 \mathrm{~km}$. The maximum POC is observed to be about $2 \mathrm{~km}$ below the mean CPT altitude $(\sim 17 \mathrm{~km})$ and above $1.0 \mathrm{~km}$ of the mean COT altitude. That is the peak of the POC mostly confined within the TTL. It is because the TTL is primarily characterized by very low temperature and minute water vapor such that the moist adiabatic lapse rate approaches the dry adiabatic lapse rate; thus, TTL is relatively stably-stratified when compared to the troposphere below it (Fueglistaler et al., 2009). According to the dehydration mechanism, the slow ascent of the TTL air parcel having minute water vapor gets freeze-dried due to low temperature leading to the frequent formation of cirrus clouds in the TTL (Jensen et al., 2013; McFarquhar et al., 2000).

The vertical distribution of POC of the cirrus clouds during different seasons shows unique characteristics. First of all, the POC varies significantly among the seasons, with minimum occurrence during the winter season and maximum occurrence during the rest of the seasons. The maximum POC is found to be about 19\%, 29\%, 25\%, and 26\% during DJF, MAM, JJA, 
and SON, respectively. Secondly, the peak of the POC occurs at different altitudes during different seasons. The altitude of maximum POC is at $15.5 \mathrm{~km}$ during DJF, $15.0 \mathrm{~km}$ during MAM, $15.0 \mathrm{~km}, 12.0 \mathrm{~km}$ during JJA, and $13.0 \mathrm{~km}$ during SON. Thus, the peak POC is higher altitude during the winter and pre-monsoon seasons and at the lower altitude during the SW and NE monsoon seasons. Third and lastly, the vertical structures of the POC are unique during different seasons. $\mathrm{km}$ to the altitude of $15.5 \mathrm{~km}$ and above, it drastically decreases up to $17 \mathrm{~km}$ with negligible or a few occurrences above it. The vertical profile of the POC during the pre-monsoon season is different from the winter season. In this season, the occurrence increases gradually from the altitude above $8 \mathrm{~km}$ to $15 \mathrm{~km}$ and gradually decreases up to $18 \mathrm{~km}$. Unlike the winter season, the maximum POC during the pre-monsoon season has a relatively sharper peak which is confined within a narrow altitude region between 13 and $15 \mathrm{~km}$. Though frequent convection does not occur during the pre-monsoon season, there are deep or very deep convections even penetrating into the lower stratosphere occur especially during May month (Devasthale et al., 2010). The POC at relatively higher altitudes during the pre-monsoon season could be due to the occurrence of very deep convections. The vertical distribution of the POC during the SW monsoon season shows double peaks at the altitudes about $12 \mathrm{~km}$ and $15 \mathrm{~km}$, unlike other seasons. Generally, frequent convections ranging from shallow to deep convection occur during

510 the SW monsoon season that spurs a large amount of water vapor in the upper troposphere, causing the frequent occurrence of multiple cirrus clouds in the altitude between 12 and $15 \mathrm{~km}$. Such multiple layers of cirrus clouds could also be due to vertically propagating gravity waves (Tsuda et al., 1994; Murthy et al., 2002). In this season, the POC gradually increases from $8 \mathrm{~km}$ to $12 \mathrm{~km}$ and shows broad maximum characterizing double peak at $12 \mathrm{~km}$ and $15 \mathrm{~km}$ and then gradually decreases above it. The vertical profile of the POC during the post-monsoon (NE) season shows a gradual increase from $8 \mathrm{~km}$ to $13 \mathrm{~km}$ (peak

515 altitude cirrus clouds) and then a gradual decrease to about $17 \mathrm{~km}$. It is interesting to find that POC shows a substantial interannual variation with higher POC during the year 2016 when compared to 2017-2018. This higher occurrence of the POC during 2016 is mainly contributed from higher POC observed on the winter and SW monsoon seasons 2016. POC during the pre-monsoon and NE monsoon seasons does not show such large intraseasonal variation as observed during the winter and SW monsoon seasons.

520 3.5 Interannual variation of the POC

As mentioned earlier, the seasonal variation of the POC with maxima during the SW monsoon season and minima during the winter season is well known over the Asian monsoon region. The seasonal feature of the POC is attributed due to the SW monsoon, which provides an enormous amount of water vapor to the upper troposphere. Here, we have obtained the monthly POC, monthly duration of total hours of lidar observations and cirrus observations, and monthly mean CPT and COT altitudes for the years 2016, 2017, and 2018, as shown in Figure 9. As mentioned earlier, in total, 11778 hours lidar was operated, out of which 5002 hours (that is about 42.5\% of times) of cirrus clouds were observed over the period 2016-2018. The POC among years 2016, 2017, and 2018 differ with occurrence 55.9\%, 38.7\%, and 36.8\%, respectively. We have provided the details of the POC along with CPT and COT altitudes and TTL thickness (TTLt) during different seasons and for the 
overall year during 2016, 2017, and 2018 as listed in the Supplementary Table ST1. The years 2017 and 2018 show about the same percentage occurrence (38\%); however, POC during 2016 is about $56 \%$ indicating a large interannual variation in the POC over Kattankulathur. The POC decreases from $72 \%$ to $46 \%$ during the SW monsoon season 2016 to 2018. The POC during pre-monsoon and post-monsoon seasons of 2016 are $\sim 55 \%$ and $\sim 48 \%$, respectively, which are decreased by $\sim 12 \%$ and $\sim 13.5 \%$ during 2018 . It is to be noted that the TTL has been increased during the pre-monsoon season 2016-2018. Note that this feature was not seen in other seasons. Interestingly, the TTL thickness shows a decrease with increasing POC, especially

535 during the SW monsoon season.

In general, the maximum POC is found to be during February, May to September, and November, while the minimum POC is during March and October. The observed higher POC during May to September and November appears related to the convective activities during SW monsoon and NE monsoon, respectively. We have examined the monthly mean variation of the OLR over central India, throughout Tamil Nadu, and over Kattankulathur (Chennai), as shown in Supplementary Figure

540 S2. It can be seen that OLR $<240 \mathrm{~W} / \mathrm{m}^{2}$ starts to occur after May and persists till November. However, over central India, OLR $<240 \mathrm{~W} / \mathrm{m}^{2}$ occurs only during June-September. An abundance of deep convective clouds during the SW monsoon season triggers the formation of cirrus clouds from the anvil's clouds. In addition, the TEJ advects the upper-level moisture from the South China Sea and Bay of Bengal while LLJ brings moisture from the Indian sub-continent favorable for the cirrus cloud formation (Subrahmanyam et al., 2016). Higher POC observed during February may be associated with turbulence, which is prominent over the altitude of $\sim 10-18 \mathrm{~km}$ during the winter season (Satheesan and Krishna Murthy, 2002).

The vertical extent of the cirrus clouds is highly variable from month to month, as mentioned earlier. The cirrus cloud top is generally confined below the CPT altitude except during May-September when POC is occurring below the COT altitude. Similar to our results, Pan and Munchak (2011) and Pandit et al. (2014b) reported the POC above the CPT altitude. The layers of the maximum POC at $\sim 12 \mathrm{~km}$ and $\sim 15 \mathrm{~km}$ and minimum POC at $\sim 14 \mathrm{~km}$ characterizing the multiple-layer cirrus clouds during the SW monsoon seasons. Such multiple cirrus layers are attributed due to the condensation, nucleation, and subsequent freeze-drying of the moisture as a result of the slow updraft from the COT top (Meenu et al., 2011), the freezedrying of the moisture transported relatively at higher altitude due to TEJ (Das et al., 2011) and the cold temperature anomaly induced by wave activities near the tropopause (Kim et al., 2016). Though Kattankulathur is located in the rain shadow region of the SW monsoon season, it is located in the vicinity of the TEJ stream associated with upper-tropospheric circulations that

555 seem to favor the frequent occurrence of the cirrus clouds. TEJ advects an enormous amount of moisture from the Bay of Bengal as well supply of moisture from convection results in the formation of cirrus clouds over a large vertical depth.

It is important to note that the enhanced occurrence of POC during May to September has been significantly reduced in the year 2017 except for the enhancement during March to April. We also observed enhancement in the POC immediately above the COT altitude to $14 \mathrm{~km}$ from February and November. The POC is observed to be significantly reduced above the

560 COT altitude in July. The frequent occurrence of the mid-level clouds could have prevented the lidar signals from detecting cirrus clouds. In contrast to 2016 and 2017, the POC during February, August, and September 2018 was significantly reduced. 
Interestingly, the maximum POC observed at $16 \mathrm{~km}$ during April shifts to $9 \mathrm{~km}$ during July. The POC was also found to be just above the CPT altitude during 2016, which was not observed during 2017 and 2018. Such interannual variation in the POC appears related to El Nino Southern Oscillation (ENSO) and quasi-biennial oscillations (QBO). They are the important

565 factors influencing the interannual variation in the TTL cloud fractions (Tseng and Fu, 2017). During the first half of 2016, a stronger El Nino condition was observed while the rest of the rest half of 2016 and during 2017 and 2018, weak La Nina and El Nino conditions were prevailing, as shown in Supplementary Figure S3. It is to be noted that relatively stronger convection was observed during the SW monsoon 2016 (El Nino condition) compared to the SW monsoons 2017 and 2018 (La Nina conditions). However, relatively stronger convection was observed during November 2017 when compared to November 2016 and 2018. It appears that the prevalence of the convection is an important factor in such higher interannual variations of the POC over Kattankulathur. In a future study, we would like to investigate this aspect in more detail.

\section{Summary and conclusions}

Cirrus clouds play an important role in the Earth-Atmosphere radiation budget by their greenhouse and albedo effects that depend on the physical and optical properties. Therefore, a precise understanding of the physical properties (e.g., diurnal cycle, vertical extent, etc.) of cirrus cloud occurrence and cloud optical depth is a highly essential input to climate modeling and prediction. However, to the author's knowledge, there are no such studies over the Indian monsoon region on the diurnal variation of the cirrus clouds exist, mainly due to limited long-term continuous observations.

Hence, for the first time, our study presents the diurnal variation of the cirrus clouds during different seasons over the

580 NE monsoon region, Kattankulathur, located near the east coast of the Bay of Bengal. The cirrus cloud occurrence for the single and multiple layers identified by the zero-crossing method is evaluated using the MPL observations between 14:00 IST on day one to 11:00 IST on the second day over 2016-2018. The main conclusions from this study are briefly summarized as follows:

1. The cirrus cloud occurrence shows a unique diurnal structure with a higher occurrence of the single-layer cirrus in the late evening (18:00-21:00 IST) hours subjugated by the convective processes during the SW and NE monsoon seasons. While for the multiple layer cirrus, the occurrence is higher in the early morning hours (4:00-5:00 IST), subjugated by both the freeze-drying and deep convection processes.

2. The deep convection and low tropopause temperatures are crucial for the enhancement in the cirrus cloud occurrences. We calculated the frequency occurrence of the brightness temperature $<240 \mathrm{~K}$ proxy for the convection. The results indicate that the convection that occurs more frequently from afternoon hours dominates the higher occurrence of evening single-layer cirrus clouds during SW and NE monsoon seasons. We also obtained the frequency occurrence of the CPT temperature $<191 \mathrm{~K}$ that occurs more frequently during morning hours throughout the year. This result indicates the freeze-drying process is favorable for the higher occurrence of morning multiple-layer cirrus clouds at relatively higher altitudes. 
3. The overall (single and multiple layers together) cirrus clouds occurrence shows a substantial seasonal variation. The occurrence is $\sim 10-25 \%$ during the winter season, with the highest occurrence over the altitude $\sim 14-16 \mathrm{~km}$ just below the mean CPT altitude $(17.2 \mathrm{~km})$. In this season, cirrus clouds are predominantly sub-visual, mostly in-situ generated mainly by condensation of minute water vapor due to extremely cold temperatures at relatively higher altitudes.

4. During the pre-monsoon season (March-May), cirrus cloud occurrence varies from $10 \%$ to $30 \%$. The minimum occurrence is observed during March. During April-May, the occurrence shows a significant enhancement in the altitude of 10-17 km with peak occurrence (20-30\%) at the altitude $\sim 14-15 \mathrm{~km}$, mainly confined within the TTL. The frequent thunderstorm activities during April-May appears to be the main reason for the phenomenal increase in cirrus cloud occurrence in these months.

5. During SW monsoon season, cirrus cloud occurrence is maximum $(\sim 40 \%)$ with frequent multi-layered cirrus clouds. Cirrus clouds also occur more frequently below the TTL, however, rarely above the CPT. Though Kattankulathur is located in the rain shadow region of the SW monsoon season, convection prevails. However, it is located in the TEJ core region which is favorable for the wind shear (turbulence) generated cirrus clouds. Additionally, TEJ advects an enormous amount of moisture from the Bay of Bengal as well as the supply of moisture from convection results in cirrus cloud occurrence over a large vertical extent $(\sim 8-18 \mathrm{~km})$.

6. During the NE monsoon seasons, the occurrence has a limited vertical extent. It is generally confined within the TTL with fewer or no occurrence of cirrus clouds above the CPT. Due to the weakening of the local convection, the inadequate moisture supply reduces the sustenance of cirrus clouds during October. However, a relatively higher occurrence during November appears due to the prevalence of the NE monsoon over Kattankulathur. The convection during the NE monsoon is not as strong as the SW monsoon leading to the formation of the cirrus clouds at relatively lower heights during the former season.

7. The occurrence shows a distinct interannual variability with higher occurrence during the year 2016 compared to 2017 and 2018. The occurrence during 2016, 2017, and 2018 was found to be $\sim 55.9 \%$, 38.7\%, and $36.8 \%$, respectively. We observed a stronger El Nino condition associated with relatively more vigorous convection in the first half of 2016. Whereas the rest half of 2016 and during 2017 and 2018, weak La Nina and El Nino conditions were associated with weaker convections.

The present study shows the diurnal cycle of the cirrus clouds, which will be helpful in the assessment of the climate models. Though MPL detection is limited to nocturnal cirrus clouds, it has captured the diurnal pattern in the occurrence of the single and multiple layered cirrus clouds that show the augmentation during the evening and morning hours. In a future study, we are planning to explore the satellite data simultaneous to MPL observations to unravel the day-night difference in the cirrus clouds occurrence over Kattankulathur and adjoining regions.

\section{Data availability}

MPL data used in this study are not open to the public yet. However, the data can be provided upon request to the corresponding author. 


\section{Declaration of competing interest}

The authors declare that they have no known competing financial interests or personal relationships that could have appeared to influence the work reported in this paper.

\section{Authors' Contributions}

Sanjay Kumar Mehta: Supervision, Conceptualization, Investigation, Writing- Reviewing and Editing, Saleem Ali: Data curation, Investigation, Writing- Original draft preparation, Aravindhavel Ananthavel: Data curation, Software, Investigation, T.V. Ramesh Reddy: Data curation, Investigation

\section{Acknowledgements}

This work is fully supported by Department of Science and Technology, Government of India - Science and engineering Research Board (DST-SERB) project (EMR/2015/000525). SKM wishes to thank Earth Science and Technology Cell (ESTC) under the Ministry of Earth Sciences (MoES) for MPL obsevations. One of the authors (SA) wishes to thank DST-SERB for providing fellowship for this study. SKM also thanks MHRD, Government of India, for the support from Scheme for Promotion

645 of Academic and Research Collaboration (SPARC) project (SPARC/ 2018-2019/P835/SL). SRM HPCC facility is used to process the MPL data.

\section{References}

Cadet, B., Goldfarb, L., Faduilhe, D., Baldy, S., Giraud, V., Keckhut, P. and Re, A.: A sub-tropical cirrus clouds climatology from Reunion 650 Island ( $21^{\circ} \mathrm{S}, 55^{\circ} \mathrm{E}$ ) lidar data set, , 30(3), 8-11, doi:10.1029/2002GL016342, 2003.

Corti, T., Luo, B. P., Fu, Q., Vömel, H. and Peter, T.: The impact of cirrus clouds on tropical troposphere-to-stratosphere transport, Atmos. Chem. Phys., 6(9), 2539-2547, doi:10.5194/acp-6-2539-2006, 2006.

Cziczo, D. J. and Froyd, K. D.: Sampling the composition of cirrus ice residuals, Atmos. Res., 142, 15-31, doi:10.1016/j.atmosres.2013.06.012, 2014.

655 Dai, G., Wu, S., Song, X. and Liu, L.: Optical and Geometrical Properties of Cirrus Clouds over the Tibetan Plateau Measured by Lidar and Radiosonde Sounding at the Summertime in 2014, , (December), 1-24, doi:10.1051/epjconf/201817605040, 2017.

Das, S. K., Chiang, C. W. and Nee, J. B.: Influence of tropical easterly jet on upper tropical cirrus: An observational study from CALIPSO, Aura-MLS, and NCEP/NCAR data, J. Geophys. Res. Atmos., 116(12), doi:10.1029/2011JD015923, 2011.

Dessler, A. E., Palm, S. P., Hart, W. D. and Spinhirne, J. D.: Tropopause-level thin cirrus coverage revealed by ICESat / Geoscience Laser

660 Altimeter System, , 111(August 2005), 1-10, doi:10.1029/2005JD006586, 2006.

Devasthale, A., Fueglistaler, S., Division, S., Meteorological, S. and Physics, T.: and Physics A climatological perspective of deep convection penetrating the TTL during the Indian summer monsoon from the AVHRR and MODIS instruments, , 4573-4582, doi:10.5194/acp-104573-2010, 2010.

Flynn, C. J., Mendoza, A., Zheng, Y. and Mathur, S.: Novel polarization-sensitive micropulse lidar measurement technique., Opt. Express,

665 15(6), 2785-90 [online] Available from: http://www.ncbi.nlm.nih.gov/pubmed/19532516, 2007.

Fortuin, J. P. F., Becker, C. R., Fujiwara, M., Immler, F., Kelder, H. M., Scheele, M. P., Schrems, O. and Verver, G. H. L.: Origin and transport of tropical cirrus clouds observed over Paramaribo, Suriname $\left(5.8^{\circ} \mathrm{N}, 55.2^{\circ} \mathrm{W}\right)$, J. Geophys. Res., 112(D9), D09107, doi:10.1029/2005JD006420, 2007. 
Fu, Q. and Liou, K. N.: Parameterization of the Radiative Properties of Cirrus Clouds, J. Atmos. Sci., 50(13), 2008-2025, doi:10.1175/1520-

670 0469(1993)050<2008:POTRPO >2.0.CO;2, 1993.

Fueglistaler, S., Dessler, A. E., Dunkerton, T. J., Folkins, I., Fu, Q. and Mote, P. W.: TROPICAL TROPOPAUSE LAYER, , (2008), 1-31, doi:10.1029/2008RG000267.1.INTRODUCTION, 2009.

Fujiwara, M., Iwasaki, S., Shimizu, A., Inai, Y., Shiotani, M., Hasebe, F., Matsui, I., Sugimoto, N., Okamoto, H., Nishi, N., Hamada, A., Sakazaki, T. and Yoneyama, K.: Cirrus observations in the tropical tropopause layer over the western Pacific, J. Geophys. Res., 114(D9),

675 D09304, doi:10.1029/2008JD011040, 2009.

Gouveia, D. A., Barja, B., Barbosa, H. M. J., Seifert, P., Baars, H. and Pauliquevis, T.: Optical and geometrical properties of cirrus clouds in Amazonia derived from 1 year of ground-based lidar measurements, , 3619-3636, doi:10.5194/acp-17-3619-2017, 2017.

Haladay, T. and Stephens, G.: Characteristics of tropical thin cirrus clouds deduced from joint CloudSat and CALIPSO observations, J. Geophys. Res. Atmos., 114(8), 1-13, doi:10.1029/2008JD010675, 2009.

680 Held, I. M. and Hoskins, B. J.: LARGE-SCALE EDDIES AND THE GENERAL CIRCULATION OF THE TROPOSPHERE, , C, 1985. JCA Marrero, B. B.: Cirrus Clouds Optical Properties Measured With Lidar At Camagüey, Cuba . Propiedades Ópticas de Nubes Cirros Medidas con Lidar en Camagüey, Cuba ., Opt. pura y Apl., 39(1), 11-16, 2006.

Jensen, E. J., Toon, O. B., Pfister, L. and Selkirk, H. B.: and lower by subvisible cirrus clouds near the tropical tropopause, , 23(8), 825$828,1996$.

685 Jensen, E. J., Diskin, G., Lawson, R. P., Lance, S., Bui, T. P., Hlavka, D., McGill, M., Pfister, L., Toon, O. B. and Gao, R.: Ice nucleation and dehydration in the Tropical Tropopause Layer, Proc. Natl. Acad. Sci., 110(6), 2041-2046, doi:10.1073/pnas.1217104110, 2013.

Kim, J., Grise, K. M. and Son, S.-W.: Thermal characteristics of the cold-point tropopause region in CMIP5 models, J. Geophys. Res. Atmos., 118(16), 8827-8841, doi:10.1002/jgrd.50649, 2013.

Kulkarni, P., Ramachandran, S., Bhavani Kumar, Y., Narayana Rao, D. and Krishnaiah, M.: Features of upper troposphere and lower

690 stratosphere aerosols observed by lidar over Gadanki, a tropical Indian station, J. Geophys. Res., 113(D17), D17207, doi:10.1029/2007JD009411, 2008.

Liou, K. N. K.-N.: Influence of cirrus clouds on weather and climate processes A global perspective, Mon. Weather Rev., 114, 1167-1199, doi:10.1175/1520-0493(1986)114<1167:IOCCOW>2.0.CO;2, 1986.

Liu, Z., Vaughan, M., Winker, D., Kittaka, C., Getzewich, B., Kuehn, R., Omar, A., Powell, K., Trepte, C. and Hostetler, C.: The CALIPSO

695 Lidar Cloud and Aerosol Discrimination: Version 2 Algorithm and Initial Assessment of Performance, J. Atmos. Ocean. Technol., 26(7), 1198-1213, doi:10.1175/2009JTECHA1229.1, 2009.

Lynch, D. K.: Cirrus, Oxford University Press. [online] Available from: https://books.google.co.in/books/about/Cirrus.html?id=58v1 fg4xeo8C (Accessed 25 October 2018), 2002.

Massie, S. T., Khosravi, R. and Gille, J. C.: A multidecadal study of cirrus in the tropical tropopause layer, , 118(December 2012), 7938-

700 7947, doi:10.1002/jgrd.50596, 2013.

McFarquhar, G. M., Heymsfield, A. J., Spinhirne, J. and Hart, B.: Thin and Subvisual Tropopause Tropical Cirrus: Observations and Radiative Impacts, J. Atmos. Sci., 57(1998), 1841-1853, doi:10.1175/1520-0469(2000)057<1841:TASTTC>2.0.CO;2, 2000.

Meenu, S., Rajeev, K., Parameswaran, K. and Nair, A. K. M.: Regional distribution of deep clouds and cloud top altitudes over the Indian subcontinent and the surrounding oceans, J. Geophys. Res., 115(D5), D05205, doi:10.1029/2009JD011802, 2010.

705 Meenu, S., Rajeev, K. and Parameswaran, K.: Regional and vertical distribution of semitransparent cirrus clouds over the tropical Indian region derived from CALIPSO data, J. Atmos. Solar-Terrestrial Phys., 73(13), 1967-1979, doi:10.1016/j.jastp.2011.06.007, 2011.

Motty, G. S., Satyanarayana, M., Jayeshlal, G. S., Krishnakumar, V. and Mahadevan Pillai, V. P.: Lidar observed structural characteristics of higher altitude cirrus clouds over a tropical site in Indian subcontinent region, J. Atmos. Solar-Terrestrial Phys., 179, 367-377, doi:10.1016/j.jastp.2018.08.013, 2018.

710 Murthy, B. V. K., Satheesan, K., Parameswaran, K., Sasi, M. N., Ramkumar, G., Bhavanikumar, Y., Raghunath, K. and Krishniah, M.: Equatorial waves in temperature in the altitude range 4 to $70 \mathrm{~km}$, Q. J. R. Meteorol. Soc., 128(581), 819-837, doi:10.1256/0035900021643700, 2002.

Muhsin, M., Sunilkumar, S.V., Venkat Ratnam, M., Krishna Murthy, B.V. and Parameswaran, K., 2017. Seasonal and diurnal variations of tropical tropopause layer (TTL) over the Indian Peninsula. Journal of Geophysical Research: Atmospheres, 122(23), pp.12-672.

715 Nair, A. K. M., Rajeev, K., Mishra, M. K., Thampi, B. V. and Parameswaran, K.: Multiyear lidar observations of the descending nature of tropical cirrus clouds, J. Geophys. Res. Atmos., 117(17), 1-9, doi:10.1029/2011JD017406, 2012.

Nazaryan, H., McCormick, M. P. and Menzel, W. P.: Global characterization of cirrus clouds using CALIPSO data, J. Geophys. Res. Atmos., 113(16), 1-11, doi:10.1029/2007JD009481, 2008.

Pace, G., Cacciani, M., Sarra, A., Fiocco, G. and Fua, D.: Lidar observations of equatorial cirrus clouds at Mahe, , 108, 1-12,

720 doi:10.1029/2002JD002710, 2003.

Pal, S. R., Steinbrecht, W. and Carswell, A. I.: Automated method for lidar determination of cloud-base height and vertical extent, Appl. Opt., 31(10), 1488, doi:10.1364/AO.31.001488, 1992.

Pan, L. L. and Munchak, L. A.: Relationship of cloud top to the tropopause and jet structure from CALIPSO data, J. Geophys. Res. Atmos., 116(12), 1-17, doi:10.1029/2010JD015462, 2011. 
725 Pandit, A. K., Gadhavi, H., Ratnam, M. V., Jayaraman, A., Raghunath, K. and Rao, S. V. B.: Characteristics of cirrus clouds and tropical tropopause layer: Seasonal variation and long-term trends, J. Atmos. Solar-Terrestrial Phys., 121(PB), 248-256, doi:10.1016/j.jastp.2014.07.008, 2014a.

Pandit, A. K., Gadhavi, H. S., Ratnam, M. V., Raghunath, K., Rao, S. V. B. and Jayaraman, A.: Long-term trend analysis and climatology of tropical cirrus clouds using 16 years of lidar data set over Southern India, Atmos. Chem. Phys., 15(24), 13833-13848, doi:10.5194/acp-

$730 \quad 15-13833-2015,2015$.

Parameswaran, K., SunilKumar, S. V., Krishna Murthy, B. V., Satheesan, K., Bhavani Kumar, Y., Krishnaiah, M. and Nair, P. R.: Lidar observations of cirrus cloud near the tropical tropopause: Temporal variations and association with tropospheric turbulence, Atmos. Res., 69(1-2), 29-49, doi:10.1016/j.atmosres.2003.08.002, 2003.

Platt, C. M., Young, S. A., Carswell, A. I., Pal, S. R., McCormick, M. P., Winker, D. M., DelGuasta, M., Stefanutti, L., Eberhard, W. L.,

735 Hardesty, M., Flamant, P. H., Valentin, R., Forgan, B., Gimmestad, G. G., Jäger, H., Khmelevtsov, S. S., Kolev, I., Kaprieolev, B., Lu, D., Sassen, K., Shamanaev, V. S., Uchino, O., Mizuno, Y., Wandinger, U., Weitkamp, C., Ansmann, A., Wooldridge, C., Platt, C. M., Young, S. A., Carswell, A. I., Pal, S. R., McCormick, M. P., Winker, D. M., DelGuasta, M., Stefanutti, L., Eberhard, W. L., Hardesty, M., Flamant, P. H., Valentin, R., Forgan, B., Gimmestad, G. G., Jäger, H., Khmelevtsov, S. S., Kolev, I., Kaprieolev, B., Lu, D., Sassen, K., Shamanaev, V. S., Uchino, O., Mizuno, Y., Wandinger, U., Weitkamp, C., Ansmann, A. and Wooldridge, C.: The Experimental Cloud Lidar Pilot Study

740 (ECLIPS) for Cloud-Radiation Research, Bull. Am. Meteorol. Soc., 75(9), 1635-1654, doi:10.1175/15200477(1994)075<1635:TECLPS >2.0.CO;2, 1994.

Podglajen, A., Plougonven, R., Hertzog, A. and Jensen, E.: Impact of gravity waves on the motion and distribution of atmospheric ice particles, Atmos. Chem. Phys., 18(14), 10799-10823, doi:10.5194/acp-18-10799-2018, 2018.

Randel, W. J., Garcia, R. R. and Wu, F.: Time-Dependent Upwelling in the Tropical Lower Stratosphere Estimated from the Zonal-Mean

745 Momentum Budget, J. Atmos. Sci., 59(13), 2141-2152, doi:10.1175/1520-0469(2002)059<2141:tduitt>2.0.co;2, 2002.

Riese, M., Ploeger, F., Rap, A., Vogel, B., Konopka, P., Dameris, M. and Forster, P.: Impact of uncertainties in atmospheric mixing on simulated UTLS composition and related radiative effects, , 117(March), 1-10, doi:10.1029/2012JD017751, 2012.

Sassen, K. and Benson, S.: A Midlatitude Cirrus Cloud Climatology from the Facility for Atmospheric Remote Sensing. Part II: Microphysical Properties Derived from Lidar Depolarization, J. Atmos. Sci., 58(Sassen 1991), 2103-2112, doi:10.1175/1520-

750 0469(2001)058<2103:AMCCCF $>2.0$. CO;2, 2001.

Sassen, K., Wang, L., Starr, D. O., Comstock, J. M. and Quante, M.: A Midlatitude Cirrus Cloud Climatology from the Facility for Atmospheric Remote Sensing. Part V: Cloud Structural Properties, J. Atmos. Sci., 64(7), 2483-2501, doi:10.1175/JAS3949.1, 2007.

Sassen, K., Wang, Z. and Liu, D.: Global distribution of cirrus clouds from CloudSat/Cloud-Aerosol Lidar and Infrared Pathfinder Satellite Observations (CALIPSO) measurements, J. Geophys. Res., 113, D00A12, doi:10.1029/2008JD009972, 2008a.

755 Sassen, K., Wang, Z. and Liu, D.: Global distribution of cirrus clouds from CloudSat / Cloud-Aerosol Lidar and Infrared Pathfinder Satellite Observations ( CALIPSO ) measurements, , 113, 1-12, doi:10.1029/2008JD009972, 2008b.

Sassen, K., Wang, Z. and Liu, D.: Cirrus clouds and deep convection in the tropics: Insights from CALIPSO and CloudSat, J. Geophys. Res. Atmos., 114(21), 1-11, doi:10.1029/2009JD011916, 2009.

Satheesan, K. and Murthy, B. V. K.: Turbulence parameters in the tropical troposphere and lower stratosphere, , 107, 1-13, 2002.

760 Seifert, P., Ansmann, A., Müller, D., Wandinger, U., Althausen, D., Heymsfield, A. J., Massie, S. T. and Schmitt, C.: Cirrus optical properties observed with lidar, radiosonde, and satellite over the tropical Indian Ocean during the aerosol-polluted northeast and clean maritime southwest monsoon, J. Geophys. Res. Atmos., 112(17), 1-14, doi:10.1029/2006JD008352, 2007.

Sivakumar, V., Bhavanikumar, Y., Rao, P. B., Mizutani, K., Aoki, T., Yasui, M. and Itabe, T.: Lidar observed characteristics of the tropical cirrus clouds, Radio Sci., 38(6), n/a-n/a, doi:10.1029/2002RS002719, 2003.

765 Spinhirne, J. D., Palm, S. P., Hart, W. D., Hlavka, D. L. and Welton, E. J.: Cloud and aerosol measurements from GLAS : Overview and initial results, , 32, 1-5, doi:10.1029/2005GL023507, 2005.

Stephens, Graeme L.,Tsay,Si-Chee, Stackhouse, Paul W., Flatau, P. j.: The Relevance of the Microphysical and Radiative Properties of Cirrus Clouds to Climate and Climatic Feedback, doi:10.1175/1520-0469(1990) 047<1742:TROTMA>2.0.CO;2, 1990.

Stephens, G. L. and Webster, P. J.: Clouds and Climate: Sensitivity of Simple Systems, J. Atmos. Sci., 38(2), 235-247, doi:10.1175/1520-

770 0469(1981)038<0235:CACSOS $>2.0$. CO;2, 1981.

Subrahmanyam, K. V and Kumar, K. K.: CloudSat observations of cloud-type distribution over the Indian Atmospheric summer monsoon region Atmospheric, , doi:10.5194/angeo-31-1155-2013, 2013.

Sunil Kumar, S. V., Parameswaran, K. and Krishna Murthy, B. V.: Lidar observations of cirrus cloud near the tropical tropopause: General features, Atmos. Res., 66(3), 203-227, doi:10.1016/S0169-8095(02)00159-X, 2003.

775 Sunilkumar, S. V., Parameswaran, K., Rajeev, K., Krishna Murthy, B. V., Meenu, S., Mehta, S. K. and Babu, A.: Semitransparent cirrus clouds in the tropical tropopause layer during two contrasting seasons, J. Atmos. Solar-Terrestrial Phys., 72(9-10), 745-762, doi:10.1016/j.jastp.2010.03.020, 2010.

Tao, C. and Jiang, H.: Distributions of Shallow to Very Deep Precipitation-Convection in Rapidly Intensifying Tropical Cyclones, J. Clim., 28(22), 8791-8824, doi:10.1175/JCLI-D-14-00448.1, 2015.

780 Tseng, H.-H. and Fu, Q.: Tropical tropopause layer cirrus and its relation to tropopause, J. Quant. Spectrosc. Radiat. Transf., 188, 118-131, 
doi:10.1016/J.JQSRT.2016.05.029, 2017a.

Tseng, H.-H. and Fu, Q.: Tropical tropopause layer cirrus and its relation to tropopause, J. Quant. Spectrosc. Radiat. Transf., 188, 118-131, doi:10.1016/j.jqsrt.2016.05.029, 2017b.

Tsuda, T., Murayama, Y., Wiryosumarto, H., Harijono, S. W. B. and Kato, S.: Equatorial waves and diurnal tides, , 99(94), 1994.

785 Vernier, J., Fairlie, T. D., Natarajan, M., Wienhold, F. G., Bian, J., Martinsson, B. G., Crumeyrolle, S., Thomason, L. W. and Bedka, K. M.: Journal of Geophysical Research : Atmospheres, , doi:10.1002/2014JD022372.Received, 2015.

Wang, T. and Dessler, A. E.: Analysis of cirrus in the tropical tropopause layer from CALIPSO and MLS data: A water perspective, , 117(December 2011), 1-10, doi:10.1029/2011JD016442, 2012

Welton, E. J., Voss, K. J., Quinn, P. K., Flatau, P. J., Markowicz, K., Campbell, J. R., Spinhirne, J. D., Gordon, H. R. and Johnson, J. E.:

790 Measurements of aerosol vertical profiles and optical properties during INDOEX 1999 using micropulse lidars, J. Geophys. Res. Atmos., 107(19), 1-20, doi:10.1029/2000JD000038, 2002.

Winker, D. M., Hunt, W. H. and McGill, M. J.: Initial performance assessment of CALIOP, Geophys. Res. Lett., 34(19), 1-5, doi:10.1029/2007GL030135, 2007.

Winker, D. M., Vaughan, M. A., Omar, A., Hu, Y., Powell, K. A., Liu, Z., Hunt, W. H. and Young, S. A.: Overview of the CALIPSO

795 mission and CALIOP data processing algorithms, J. Atmos. Ocean. Technol., 26(11), 2310-2323, doi:10.1175/2009JTECHA1281.1, 2009. Woods, S., Lawson, R. P., Jensen, E., Bui, T. P., Thornberry, T., Rollins, A., Pfister, L. and Avery, M.: Microphysical Properties of Tropical Tropopause Layer Cirrus, J. Geophys. Res. Atmos., 123(11), 6053-6069, doi:10.1029/2017JD028068, 2018.

Wu, S., Song, X., Liu, B., Dai, G., Liu, J., Zhang, K., Qin, S., Hua, D., Gao, F. and Liu, L.: Mobile multi-wavelength polarization Raman lidar for water vapor, cloud and aerosol measurement, Opt. Express, 23(26), 33870, doi:10.1364/OE.23.033870, 2015.

800 Wylie,Donald, Jackson, Darren L,Menzel, W.Paul, Bates, J. J.: Trends in Global Cloud Cover in Two Decades of HIRS Observations, 2005. 

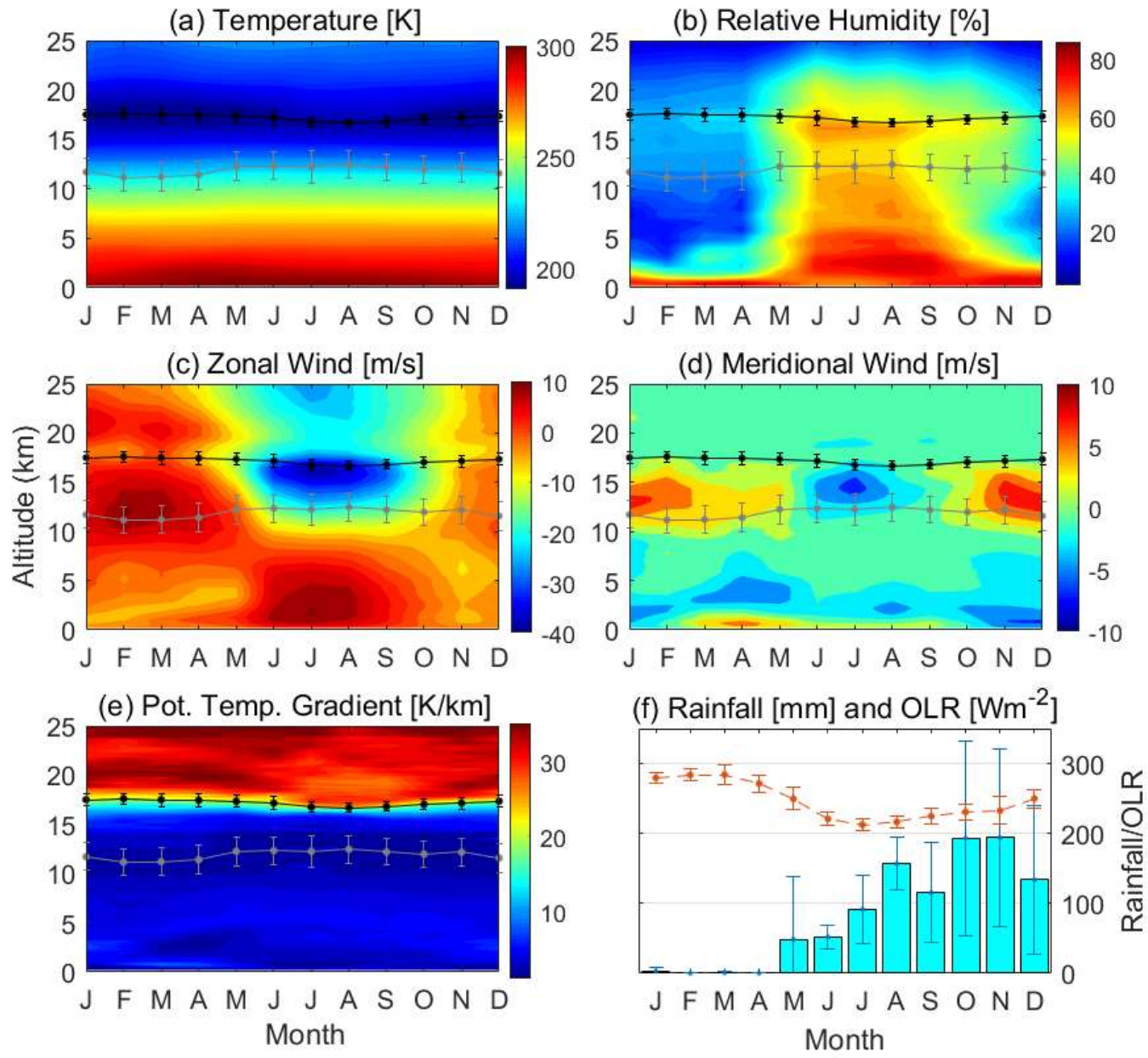

Figure 1: Time height section of the composite monthly mean (a) temperature (b) relative humidity (c) zonal wind (c) meridional wind and (e) potential temperature gradient (f) rainfall and outgoing longwave radiation (OLR) over Kattankulathur. 
(a) 12-02-2018
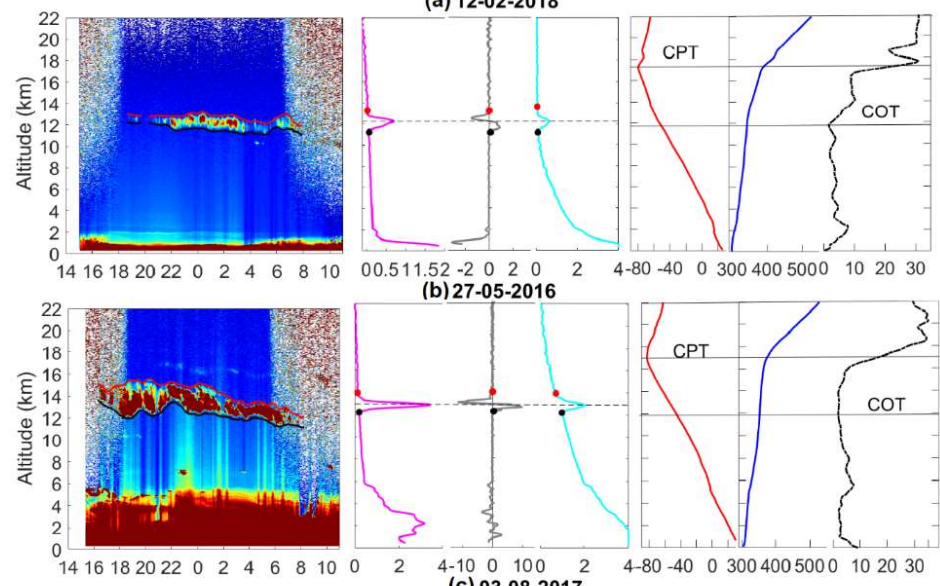

(b) $27-05-2016$
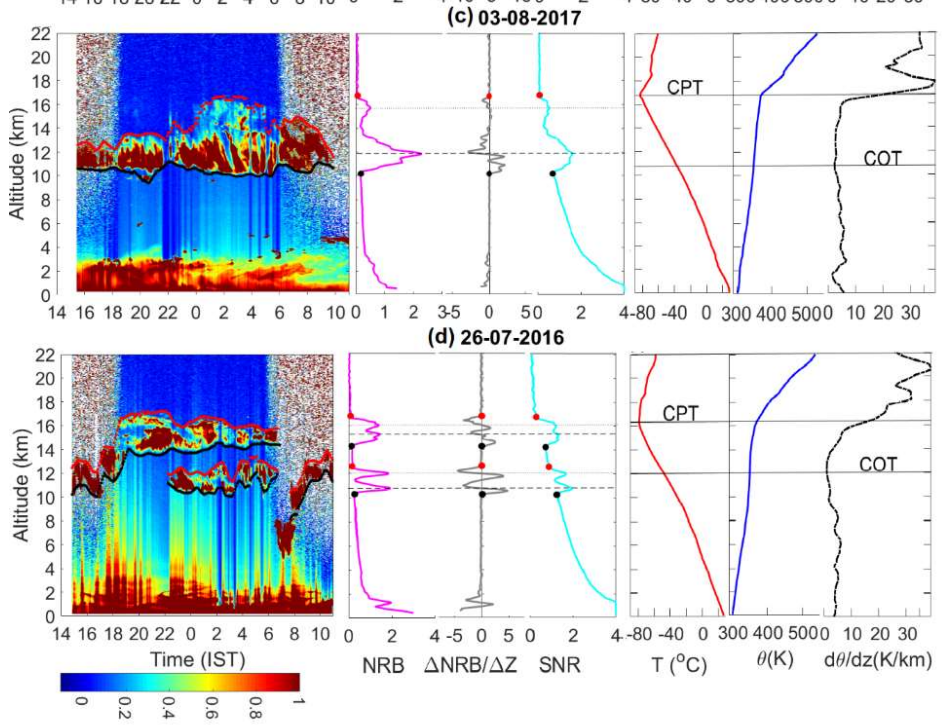

Figure 2: Time height section of the normalized backscattered (NRB) signals over the altitude $0.3-22 \mathrm{~km}$ observed on 15:00 IST on the first day to 11:00 IST on the second day. The vertical profiles of the NRB, the gradient of NRB and SNR signals at 01:30 IST) using MPL over Kattankulathur along with the daily mean temperature, potential temperature, and potential temperature gradient using radiosonde observation over Meenambakkam for different types of the cirrus clouds cases (a) laminar cirrus (12-02-2018) (b) descending cirrus (27-05-2016) (c) broad cirrus (03-08-2017), and (d) multi-layered cirrus clouds (26-07-2016). Red and black dots denote the cirrus cloud top and base of the cloud layers, respectively. Dashed lines indicate the peak altitudes of the cirrus layers. Dotted horizontal lines indicate the associated secondary peak with the main peak. Cold point tropopause (CPT) and convective tropopause (COT) are also shown. 
830
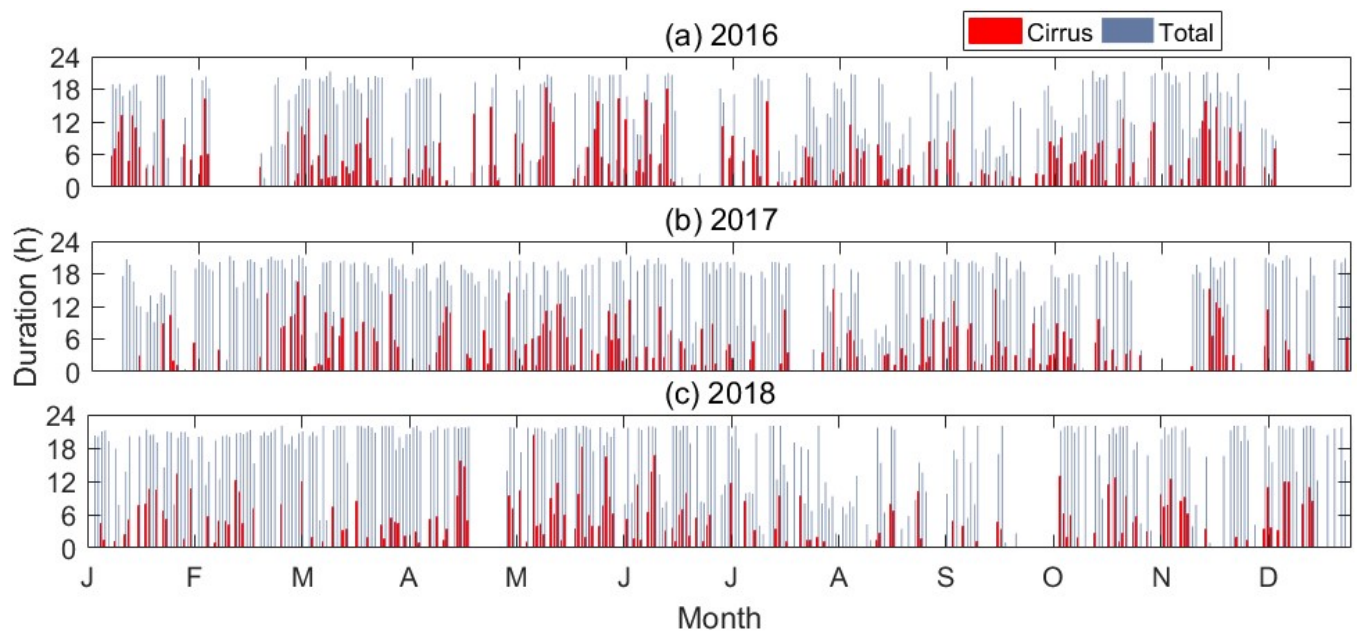

Figure 3: The day-to-day total duration of the cirrus clouds (single layer) occurrence and the total duration of MPL observations during (a) 2016, (a) 2017, and (c) 2018. 


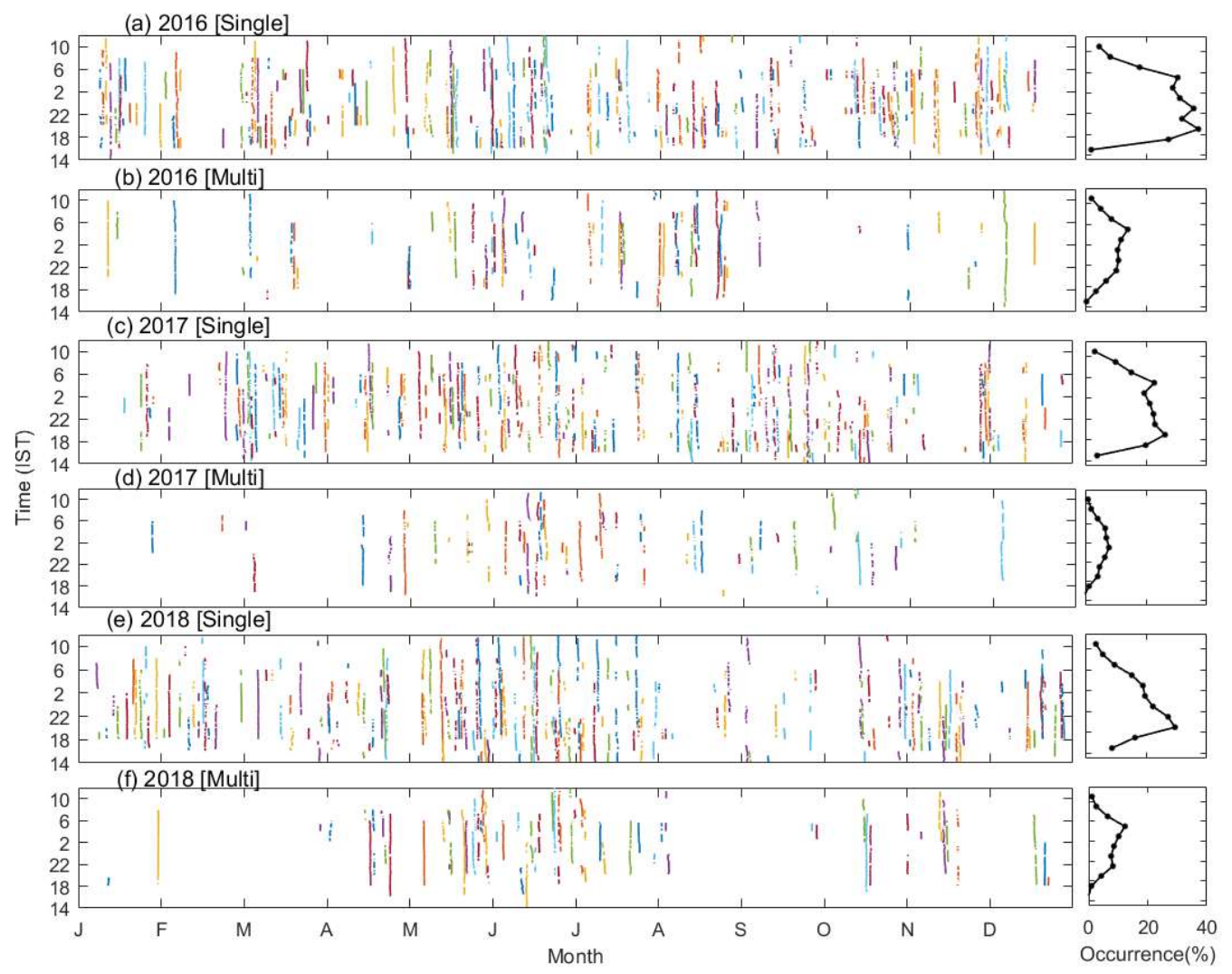

Figure 4: The day-to-day occurrence of the cirrus clouds from 14:00 IST on day one to 11:00 IST on day two and overall percentage occurrence for (a) single and (b) multi-layer cirrus clouds during 2016. (c-d) and (e-f) is the same as (a-b) but observed during 2017 and 2018 , respectively. 

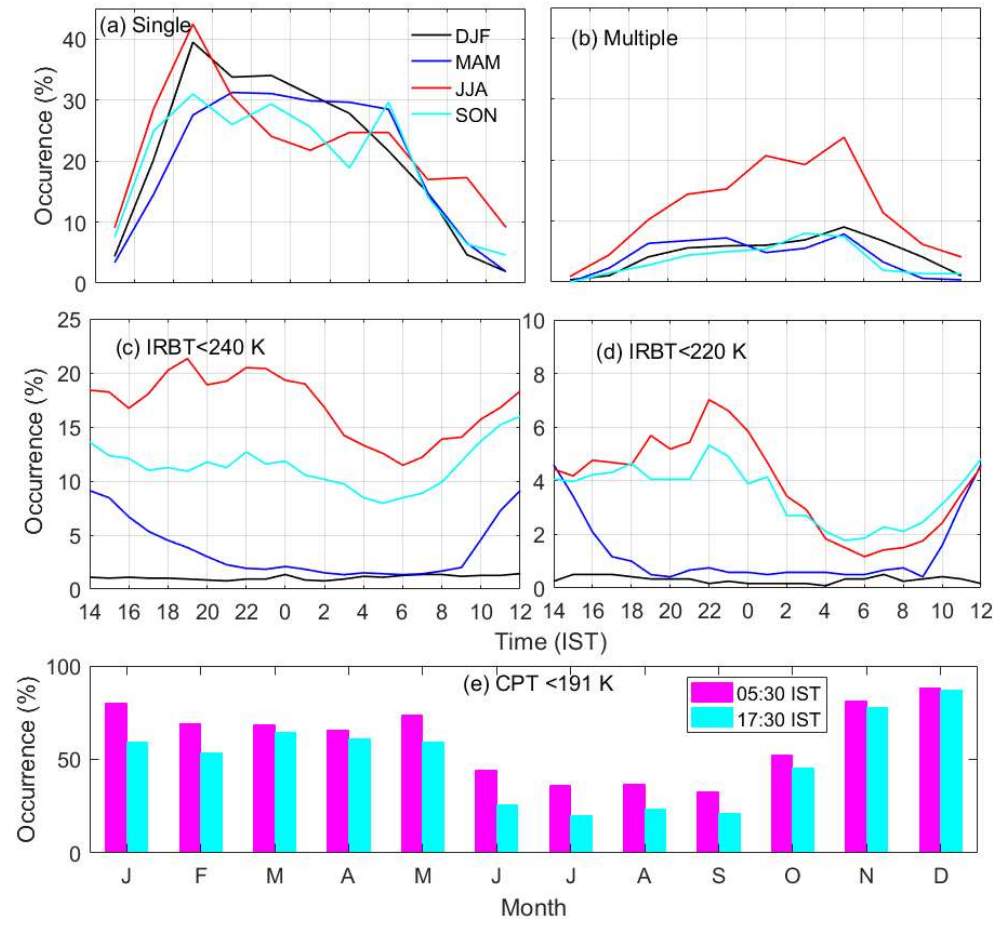

Figure 5: Diurnal variation of the percentage occurrence for (a) single and (b) multi-layer cirrus clouds, (c) IRBT less than $240 \mathrm{~K}$, and (d) IRBT less than $220 \mathrm{~K}$ during different seasons over 2016-2018. (e) Month-wise percentage occurrence of the CPT temperature less than $191 \mathrm{~K}$ at 05:00 IST and 17:30 IST over 2016-2018. 

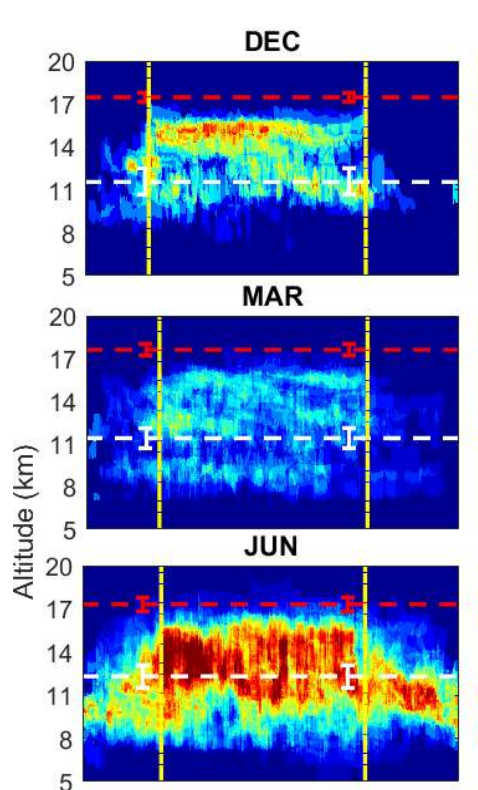

SEP

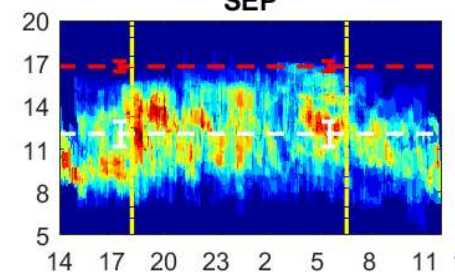

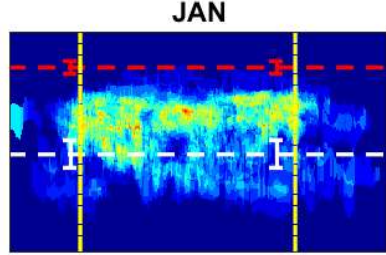

APR

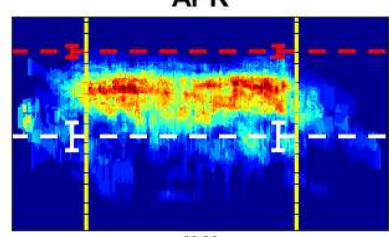

JUL

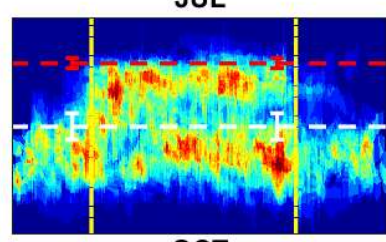

OCT

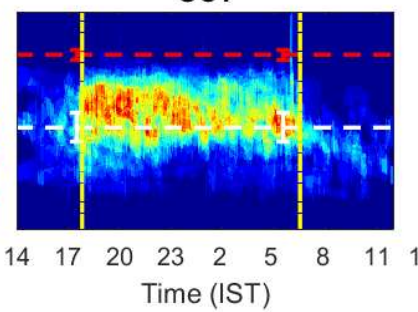

FEB
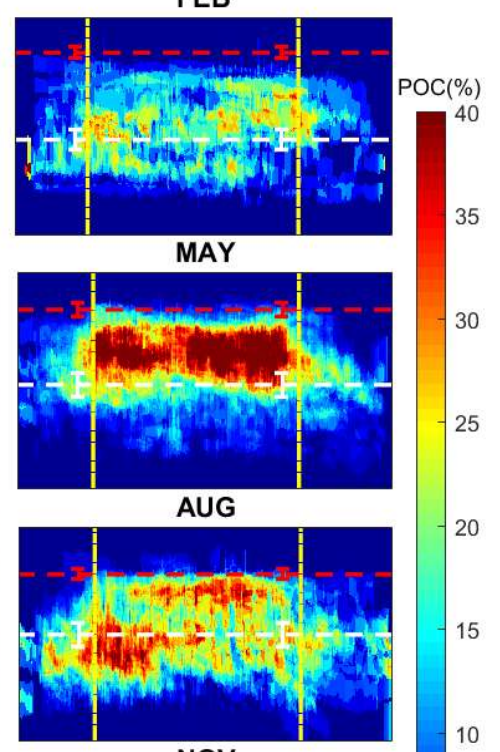

NOV

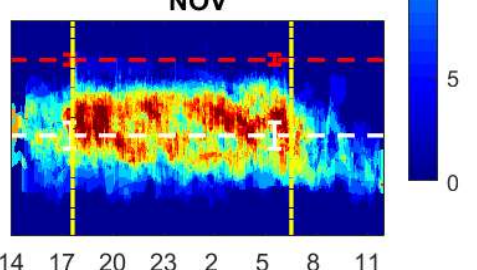

Figure 6: Monthly occurrence of cirrus clouds as a function of time and altitude from 2016 to 2018 . The mean CPT (red line) and COT (white line) altitudes for the corresponding months are also embedded. The standard deviation of the CPT altitude at 17:30 IST and 05:30 IST is also shown. Vertical dashed lines indicate the sunset and sunrise timings. 
(a) Percentage of Occurrence (2016-2018)
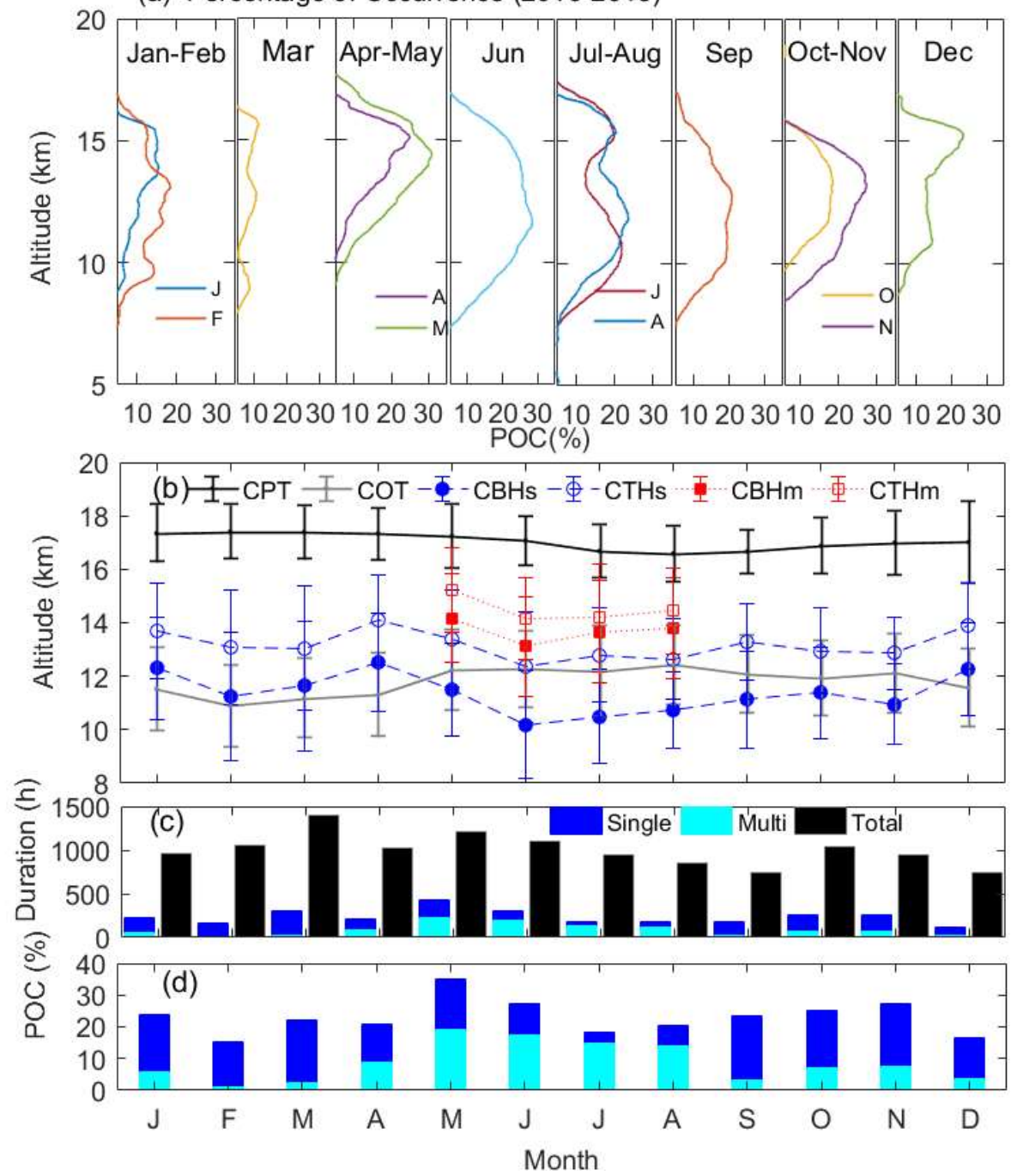

Figure 7: (a) Monthwise variation of the altitude extent of the POC, (b) monthly mean and standard deviations of the altitudes of cloud base and top, CPT and COT, (c) monthwise total observations of MPL and (d) cirrus the occurrence of the single and multi-layered clouds over the period 2016-2018. 
935

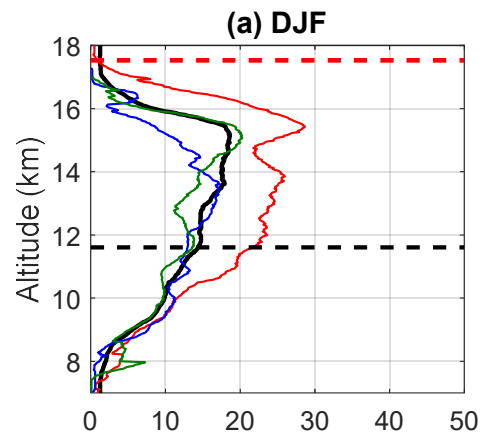

(c) JJA

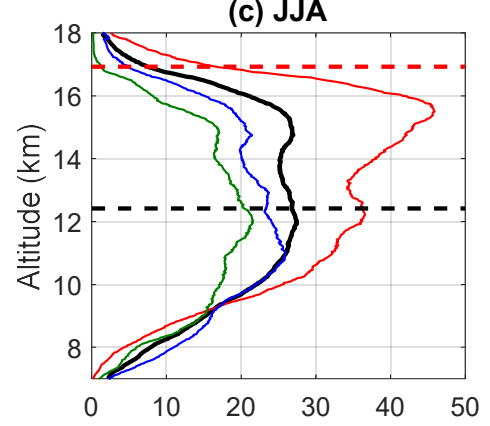

(b) MAM

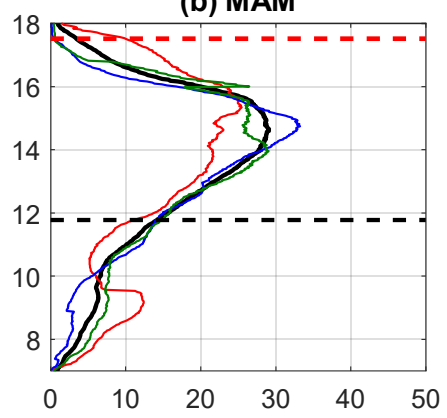

(d) SON

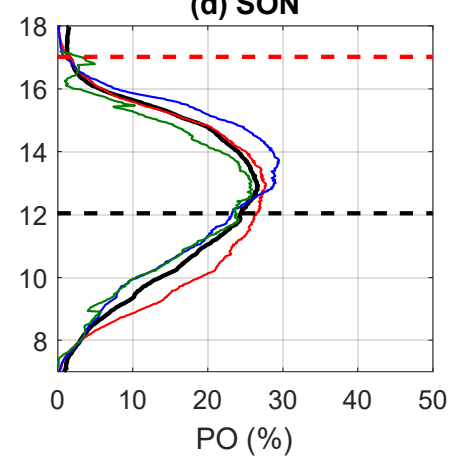

(e) Annual

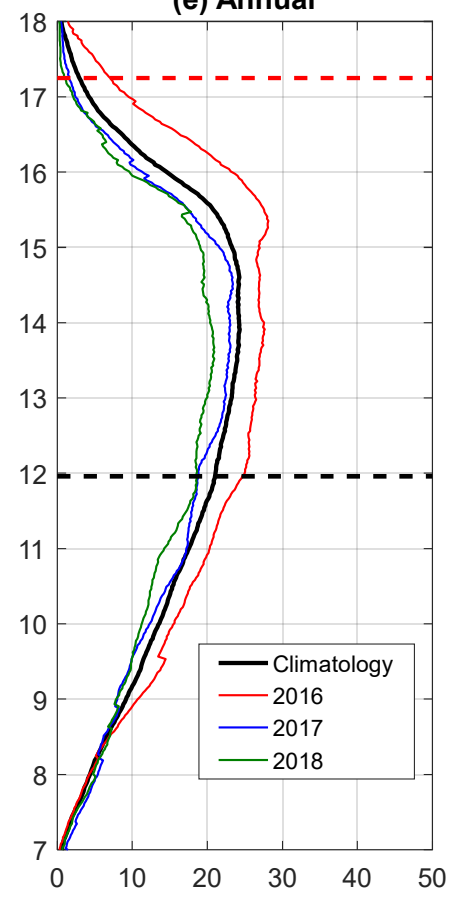

Figure 8: The vertical profile of the POC obtained using MPL during 2016 to 2018 averaged in between 19:00 IST to 05:00 IST (a) over the whole year, (b) during winter (DJF), (c) pre-monsoon (MAM), (d) monsoon (JJA), (e) post-monsoon seasons. The red and black dotted lines correspond to the $\mathrm{CPH}$ and $\mathrm{COH}$, respectively, in a given season. 


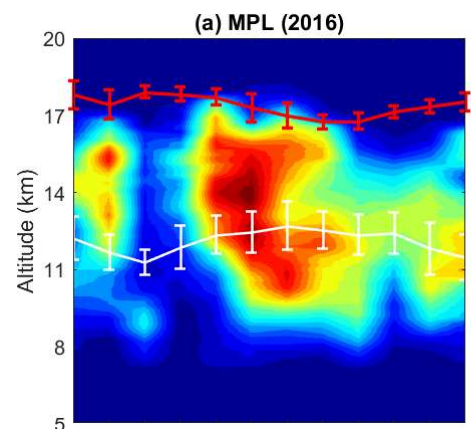

(d)

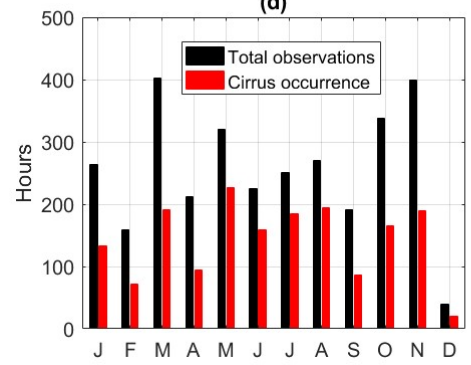

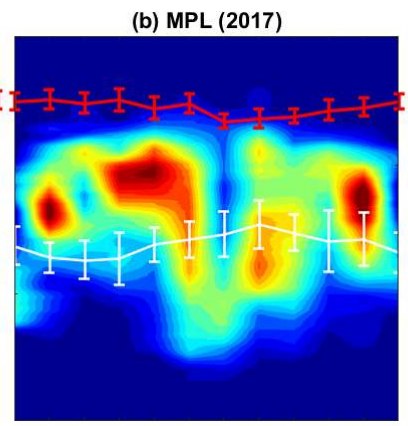

(e)
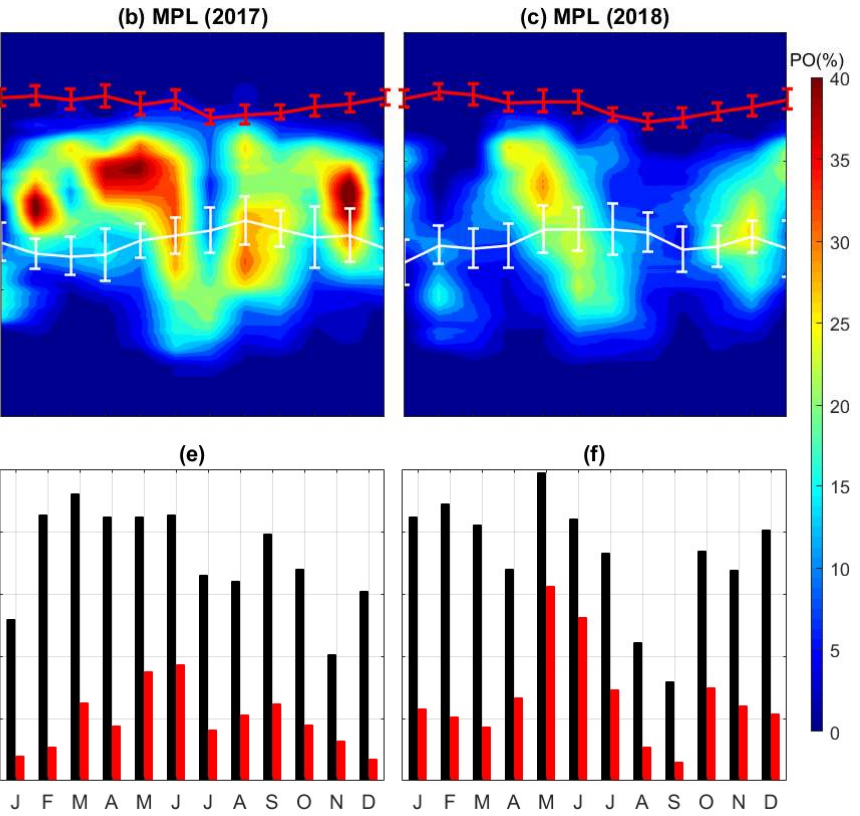

Figure 9: Monthly variation of the POC as a function of altitude during (a) 2016, (b) 2017 and (c) 2018. Monthly mean CPT altitude (red line) and $\mathrm{COH}$ (white line) with their standard deviations. (d-f) Total hours of lidar operation (black bars) and the available 965 cirrus observation (red bars) for the corresponding year. 